Provided for non-commercial research and education use. Not for reproduction, distribution or commercial use.

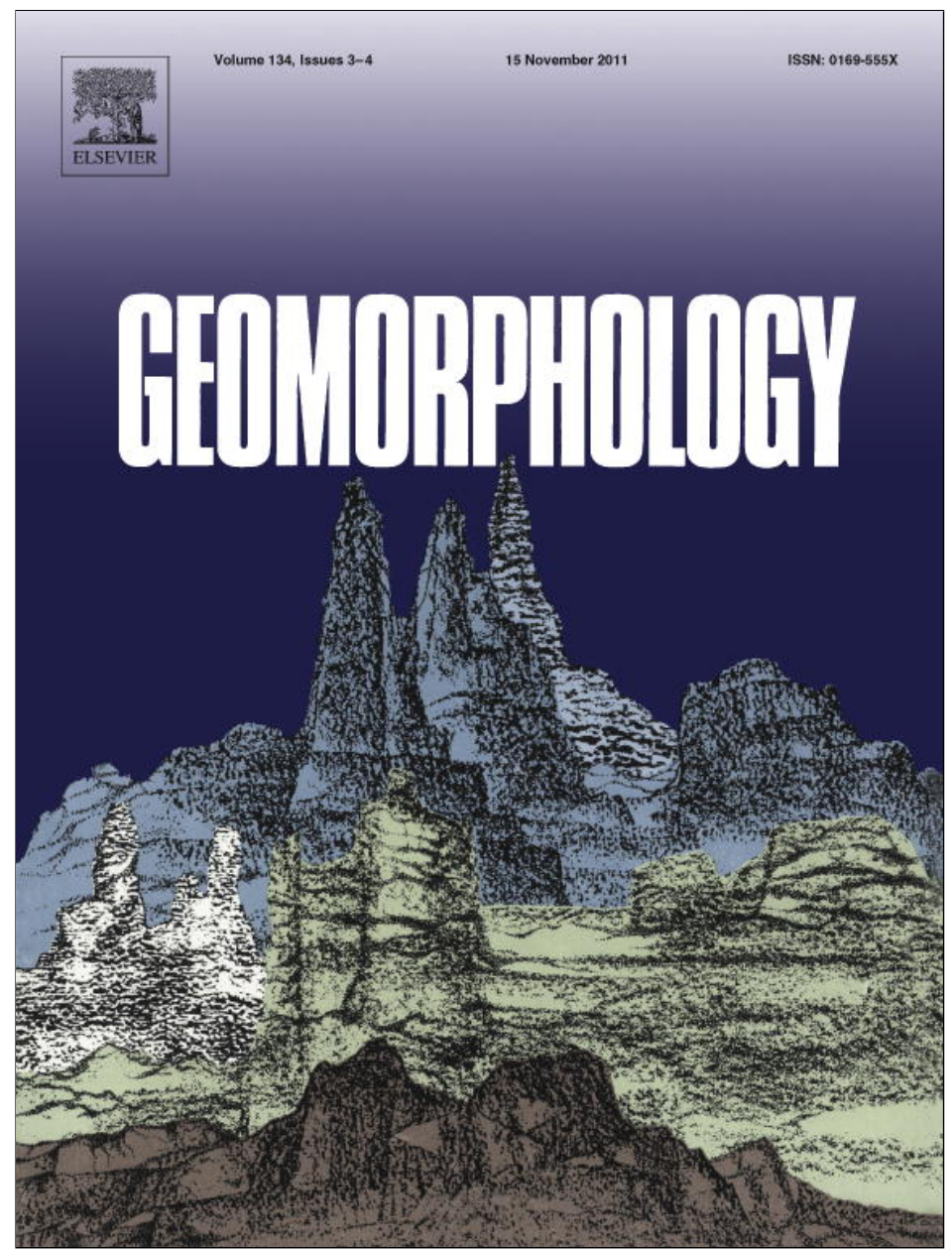

This article appeared in a journal published by Elsevier. The attached copy is furnished to the author for internal non-commercial research and education use, including for instruction at the authors institution and sharing with colleagues.

Other uses, including reproduction and distribution, or selling or licensing copies, or posting to personal, institutional or third party websites are prohibited.

In most cases authors are permitted to post their version of the article (e.g. in Word or Tex form) to their personal website or institutional repository. Authors requiring further information regarding Elsevier's archiving and manuscript policies are encouraged to visit:

http://www.elsevier.com/copyright 


\title{
Polygon pattern geomorphometry on Svalbard (Norway) and western Utopia Planitia (Mars) using high-resolution stereo remote-sensing data
}

\author{
M. Ulrich ${ }^{\text {a,* }}$, E. Hauber ${ }^{\text {b }}$, U. Herzschuh ${ }^{\text {a }}$, S. Härtel ${ }^{\text {c }}$, L. Schirrmeister ${ }^{\text {a }}$ \\ a Alfred Wegener Institute for Polar and Marine Research, Research Unit Potsdam, Telegrafenberg A45, 14473 Potsdam, Germany \\ b Institute for Planetary Research, German Aerospace Center (DLR), Rutherfordstr. 2, 12489 Berlin, Germany \\ ' Institute of Geography, University of Leipzig, Johannisallee 19a, 04103 Leipzig, Germany
}

\section{A R T I C L E I N F O}

\section{Article history:}

Received 2 March 2011

Received in revised form 29 June 2011

Accepted 3 July 2011

Available online 23 July 2011

\section{Keywords:}

Patterned ground

Permafrost characteristic

Quantitative terrain analysis

Multivariate statistic

Svalbard

Mars

\begin{abstract}
A B S T R A C T
Polygonal systems formed by thermal contraction cracking are complex landscape features widespread in terrestrial periglacial regions. The manner in which cracking occurs is controlled by various environmental factors and determines dimension, shape, and orientation of polygons. Analogous small-scale features are ubiquitous in Martian mid- and high-latitudes, and they are also inferred to originate from thermal contraction cracking. We studied the geomorphometry of polygonally-patterned ground on Svalbard to draw a terrestrial analogy to small-scale polygonal structures in scalloped terrain in Martian mid-latitudes. We performed a comparative quantitative terrain analysis based on high-resolution stereo remote-sensing data (HRSC-AX and HiRISE) in combination with terrestrial field data and multivariate statistics to determine the relationship of polygon geomorphometry to local environmental conditions. Results show that polygonal structures on Svalbard and in Utopia Planitia on Mars are similar with respect to their size and shape. A comparable thermal contraction cracking genesis is likely. Polygon evolution, however, is strongly related to regional and local landscape dynamics. Individual polygon dimensions and orthogonality vary according to age, thermal contraction cracking activity, and local subsurface conditions. Based on these findings, the effects of specific past and current environmental conditions on polygon formation on Mars must be considered. On both Earth and Mars, the smallest polygons represent young, recently-active low-centered polygons that formed in fine-grained ice-rich material. Small, low-centered Martian polygons show the closest analogy to terrestrial low-centered ice-wedge polygons. The formation of composite wedges could have occurred as a result of local geomorphological conditions during past Martian orbital configurations. Larger polygons reflect past climate conditions on both Earth and Mars. The present degradation of these polygons depends on relief and topographical situation. On Svalbard the thawing of ice wedges degrades high-centered polygons; in contrast, the present appearance of polygons in Utopia Planitia is primarily the result of contemporary dry degradation processes.
\end{abstract}

(c) 2011 Elsevier B.V. All rights reserved.

\section{Introduction and background}

Many landforms on Mars show similarities with periglacial features on Earth. On Earth these landforms reflect the effects of cold-climate conditions often in connection with permafrost dynamics. However, some of the periglacial features on Mars seem inconsistent with the prevailing Martian hydrological and climatic conditions because, like on Earth, water must have played an important role during their formation. The study of their characteristics, distribution, and spatial associations would therefore allow conclusions to be drawn about the climate history of Mars; thus, such a study can be used to indicate past and present environmental conditions. For instance, polygonal surface structures are a wide-

\footnotetext{
* Corresponding author. Tel.: + 49331 2882156; fax: + 493312882188 E-mail address: Mathias.Ulrich@awi.de (M. Ulrich).
}

spread phenomenon in periglacial landscapes on both Earth and Mars. This allows several conclusions to be drawn by analogy, but leaves open an important question: are these structures morphological analogs only, or is there a genetic relationship between them?

Patterned ground with polygon diameters ranging from meters to tens of kilometers has been described for many years on Mars (e.g., Lucchitta, 1981; Mellon, 1997; Seibert and Kargel, 2001; Mangold, 2005; van Gasselt et al., 2005; Levy et al., 2009a, 2010). While medium-sized (>100 $\mathrm{m}$ in diameter) and giant polygons (several kilometers) are suggested to originate by tectonic processes (e.g., Hiesinger and Head, 2000; Yoshikawa, 2003) or by desiccation in the case of medium-sized polygons (El Maarry et al., 2010), many authors have inferred that small-scale patterns $(<100 \mathrm{~m}$ in diameter) are formed as thermal contraction polygons, analogous to terrestrial iceand sand-wedge polygons (e.g., Seibert and Kargel, 2001; Mangold, 2005; Mellon et al., 2008; Levy et al., 2009a, 2010). Recently, it could be shown by mechanical modeling that the maximum size of polygons 
formed by thermal contraction is limited to a few decameters (El Maarry et al., 2010).

Generally, the average diameters of thermal contraction polygons on Earth range between a few meters and a few decameters. Lowcentered polygons can be distinguished from high-centered polygons. Low-centered polygons are commonly characterized by outlining furrows, which are delineated by raised rims. Upturning rims form as a result of thermal expansion and lateral displacement of the activelayer (i.e., the upper soil layer which thaws seasonally) material above a growing ice or sand wedge (Mackay, 1980). High-centered polygons are the result of ice-wedge degradation followed by the enlargement and deepening of the polygon-outlining troughs (e.g., Washburn, 1979). Ice-wedge polygons are the most common type of thermal contraction polygons in more humid arctic regions. In hyper-arid polar deserts (e.g., the Antarctic ice-free areas, Canadian high Arctic), liquid water is lacking and cracks are commonly filled by eolian material or sand, building sand-wedge polygons (e.g., Péwé, 1959; Sletten et al., 2003; Bockheim et al., 2009) (Table 1). If local conditions favor the occasional support of moisture, composite wedges can develop (Murton, 1996). Special types of sand-wedge polygons described from the Antarctic Dry Valleys are high-centered sublimation polygons (Marchant et al., 2002; Marchant and Head, 2007). However, sand-wedge polygons can hardly be distinguished from icewedge polygons in the plan view (Black, 1976).

The term polygon is here used in sensu Washburn (1979), Yershov (2004), and French (2007) as a form of patterned ground indicative of continuous cold climates and the presence of permafrost. These polygonal networks are formed by thermal contraction fissures (Lachenbruch, 1962, 1966) after an initial crack is reactivated recurrently (Mackay, 1974, 1992) and widened through subsequent filling by water, sand, or soil (Péwé, 1959; Black, 1976; Sletten et al., 2003; French, 2007). The frozen ground cracks under volumetric tension due to long cold periods and a severe soil temperature drop in winter (Yershov, 2004; Christiansen, 2005; Fortier and Allard, 2005). This in turn depends on the coefficient of thermal expansion which is larger in ice-rich sediments than in ice-free sediments (Lachenbruch, 1962) (Table 1). The strength and direction of stress vectors during thermal contraction, which determine dimension, shape, and orientation of thermal contraction polygons, are controlled by various factors such as air and ground temperature variations, subsurface conditions (i.e., rheology and water/ice content), topography, and stress-free vertical surface (e.g., breaks, other cracks, terrain edges, and talik rims). Some of these factors are summarized in Table 1; these factors offer the possibility of estimating the subsurface and climate conditions that existed during polygon formation by geomorphometric properties.
Although no clear evidence for the processes responsible for the formation of small-scale polygons on Mars can yet be presented, the distribution of these polygons at middle to high latitudes (Mangold 2005; Levy et al., 2009a) and their spatial relationship to ground ice on Mars (Mangold et al., 2004) suggest that these landforms are formed by thermal contraction cracking, which is controlled by specific periglacial climatic and subsurface conditions (Levy et al., 2010). Furthermore, the relationship of likely active thermal contraction polygons to periglacial landscape features in a geomorphologic context compared to terrestrial analogs allows conclusions to be drawn about small-scale polygon origin on Mars. However, even if most of the conclusions about Martian polygon evolution are very detailed and plausible, they frequently offer only qualitative explanations. Only a few studies have been done regarding polygon geomorphometry on Mars using quantitative methods (e.g., Rossbacher, 1986; Pina et al., 2008; Dutilleul et al., 2009; Haltigin et al., 2010). Therefore, based on very-high-resolution stereo remote-sensing data, comparative quantitative terrain analysis in combination with geomorphological and sedimentological field data from terrestrial polygons was used to verify the hypothesis that polygonal structures on Earth and Mars, which are similar in appearance, originate from comparable processes. Additionally, a multivariate statistical approach has been applied to validate and compare the relationship of polygon geomorphometry to the topographical conditions of various polygonal sites from a mid-latitude region on the Martian northern hemisphere and an analogous high-arctic region in central Spitsbergen (Svalbard) (Hauber et al., 2011, in press). The main objective of this paper is, first to highlight the relationship between geomorphometric parameters of thermal contraction polygons and site-specific topographical and subsurface conditions on Earth. Second, this understanding will be applied to give insights into formation processes and subsurface conditions of small-scale polygonal patterned ground on Mars by comparison of their associated geomorphometry. Bearing in mind the regional geomorphological context of diverse polygonal fields within periglacial landscapes, this work focuses on Adventdalen (Svalbard) and on the scalloped terrain in Utopia Planitia (Mars).

\section{Characterization of study areas}

\subsection{Svalbard (Adventdalen)}

The Svalbard archipelago, and in particular its largest island, Spitsbergen (Fig. 1), exhibits a diverse inventory of periglacial landforms in close spatial proximity. Svalbard is situated in the zone of continuous permafrost (Brown et al., 1998), which is widespread primarily outside the 60\%-glacier-covered area (Humlum et al., 2003).

Table 1

Literature-based compilation of climate and subsurface conditions in relation to various thermal contraction polygon properties

\begin{tabular}{|c|c|c|c|}
\hline Indicator & Control factors & Effects & Reference \\
\hline \multirow[t]{2}{*}{ Polygon formation } & $\begin{array}{l}\text { Air and soil temperature, } \\
\text { grain size }\end{array}$ & In silt, clay, and peat: $<-3{ }^{\circ} \mathrm{C}$ in sand and gravel: $-8{ }^{\circ} \mathrm{C}$ to $-10^{\circ} \mathrm{C}$ & $\begin{array}{l}\text { Washburn (1979); Romanovskii (1985); } \\
\text { Yershov (2004) }\end{array}$ \\
\hline & Insulation & Limiting the continuous frost cracking & Washburn (1979); French (2007) \\
\hline \multirow[t]{2}{*}{ Polygon diameter } & Temperature gradient & Large gradient $\rightarrow$ harsher climate $\rightarrow$ smaller polygons & Yershov (2004); French (2007) \\
\hline & Rheology of frozen ground & $\begin{array}{l}\text { Heat conductivity (grain size, ice content) } \rightarrow \text { fine-grained, high ice } \\
\text { content } \rightarrow \text { smaller polygons }\end{array}$ & Lachenbruch $(1962,1966)$ \\
\hline \multirow[t]{3}{*}{ Polygon form } & Stress free zones & Orthogonal $\rightarrow$ near the cooling surface hexagonal $\rightarrow$ in larger distance & Romanovskii (1977) \\
\hline & Ground homogeneity & Hexagonal patterns - stress balance & Lachenbruch (1962); French (2007) \\
\hline & Stage of development & Secondary cracking $\rightarrow$ polygon subdivision $\rightarrow$ more regular and orthogonal & Lachenbruch (1966); French (2007) \\
\hline $\begin{array}{l}\text { Polygon } \\
\text { orientation }\end{array}$ & Stress relief & Oriented if stress-free vertical surfaces exist (i.e., anisotropy of strength) & Lachenbruch (1962) \\
\hline Polygon nets & Drainage & $\begin{array}{l}\text { Small nets } \rightarrow<27^{\circ} \text { slope } \\
\text { Large nets } \rightarrow \text { to } 31^{\circ} \text { slope }\end{array}$ & Washburn (1979) \\
\hline $\begin{array}{l}\text { Ice or sand wedge } \\
\text { formation }\end{array}$ & $\begin{array}{l}\text { Atmospheric and ground } \\
\text { humidity }\end{array}$ & High aridity $\rightarrow$ sand wedge polygons & Péwé (1959); Black (1976); French (2007) \\
\hline $\begin{array}{l}\text { Ice-wedge polygon } \\
\text { formation }\end{array}$ & Soil temperature, grain size & In clay $\rightarrow<-2{ }^{\circ} \mathrm{C}$, in gravels $\rightarrow<-6{ }^{\circ} \mathrm{C}$ & Romanovskii (1985) \\
\hline
\end{tabular}


Permafrost thickness ranges from $100 \mathrm{~m}$ in the valleys to around $450 \mathrm{~m}$ in the mountains (e.g., Liestøl, 1976; Isaksen et al., 2001). Permafrost ages on Svalbard are estimated to be late Holocene in the valleys and the coastal areas (Humlum et al., 2003). The permafrost temperature on Svalbard is $-2.3^{\circ} \mathrm{C}$ to $-5.6{ }^{\circ} \mathrm{C}$ (Christiansen et al., 2010), and active-layer thickness varies from a few decimeters to $1.5 \mathrm{~m}$ depending on vegetation, snow cover, and subsurface conditions (Sørbel et al., 2001).

The main study area is Adventdalen in Central Spitsbergen (Fig. 1b), a $\sim 30 \mathrm{~km}$ long and $\sim 4 \mathrm{~km}$ wide U-shaped valley, which extends eastward from Svalbard's main town Longyearbyen $\left(78^{\circ} 13^{\prime}\right.$ $00^{\prime \prime} \mathrm{N}, 15^{\circ} 38^{\prime} 00^{\prime \prime} \mathrm{E}$ ). The area, deglaciated around $10 \mathrm{ka} \mathrm{BP}$ (Mangerud et al., 1992), is one of the driest regions on Svalbard. The annual precipitation reaches only $\sim 180 \mathrm{~mm}$ and the mean annual air temperature (MAAT) is around $-6{ }^{\circ} \mathrm{C}$ (Hanssen-Bauer and Førland, 1998). The geology of the Adventdalen area is characterized by Jurassic and Cretaceous sandstones, siltstones, and shales. Most of the bedrock massifs bordering Adventdalen belong to the Helvetiafjellet and Carolinefjellet formations (Dallmann et al., 2001). On the valley bottom, fine-grained loess-like deposits, most likely derived by deflation and local deposition of fluvial sediments, cover exposed terraces (Bryant, 1982). The patchy vegetation cover is dominated by mosses, herbs, and shallow shrubs. On exposed dry areas, which are affected by wind action, the vegetation is very sparse. The valley bottom is characterized by pingos (i.e., ice-cored mounds) and icewedge polygons. Studies of polygonal patterned ground in the Adventdalen range from geomorphological and sedimentological surveys (e.g., Matsuoka and Hirakawa, 1993; Sørbel and Tolgensbakk, 2002) to thermal contraction cracking monitoring (e.g., Matsuoka., 1999; Christiansen, 2005).
Our study focuses on four polygon fields (AD1-AD4) distributed across almost the whole of Adventdalen (Fig. 1c). The sites were chosen in the field in accordance with changes in morphology, topography, and related surficial sediment material given in the map of Tolgensbakk et al. (2001), which is explained in detail by Sørbel et al. (2001). Site AD1 is located between 11 and $15 \mathrm{~m}$ a.s.l. on a river terrace near Longyearbyen. This site, which has been well investigated by researchers of the University Center of Svalbard (UNIS), is characterized by low-centered polygons (Christiansen, 2005). Site AD2 is located between 79 and $114 \mathrm{~m}$ a.s.l. and consists of high-centered polygons. High-centered polygons also characterize the sparsely-vegetated site AD3 (82 to $112 \mathrm{~m}$ a.s.l.). Site AD4 is located at the highest elevation between 139 and $169 \mathrm{~m}$ a.s.l.

\subsection{Mars (Utopia Planitia, UP)}

The Martian study site was selected on the northern hemisphere of Mars in western Utopia Planitia (UP) (Fig. 2) due to the availability of appropriate data (see Section 3.2.) and our previous studies (Ulrich et al., 2010). Furthermore, various periglacial-like features have been observed in the region, e.g., polygonal structures, scalloped depressions, and small mounds (e.g., Soare et al., 2005; Morgenstern et al., 2007; Burr et al., 2009; de Pablo and Komatsu, 2009; Lefort et al., 2009; Levy et al., 2009b; Ulrich et al., 2010; Séjourné et al., 2011). These landforms are associated in a geomorphological context, suggesting the existence of ice-rich ground (e.g., Morgenstern et al., 2007; Lefort et al., 2009; Ulrich et al., 2010). Present surface temperatures in the region have been detected to range from $\sim 180 \mathrm{~K}$ in winter to $\sim 240 \mathrm{~K}$ in summer (Morgenstern et al., 2007), but thermal modeling indicates they could reach $\sim 260 \mathrm{~K}$ during summer (Ulrich et al., 2010). Geologically, the region is characterized by two main
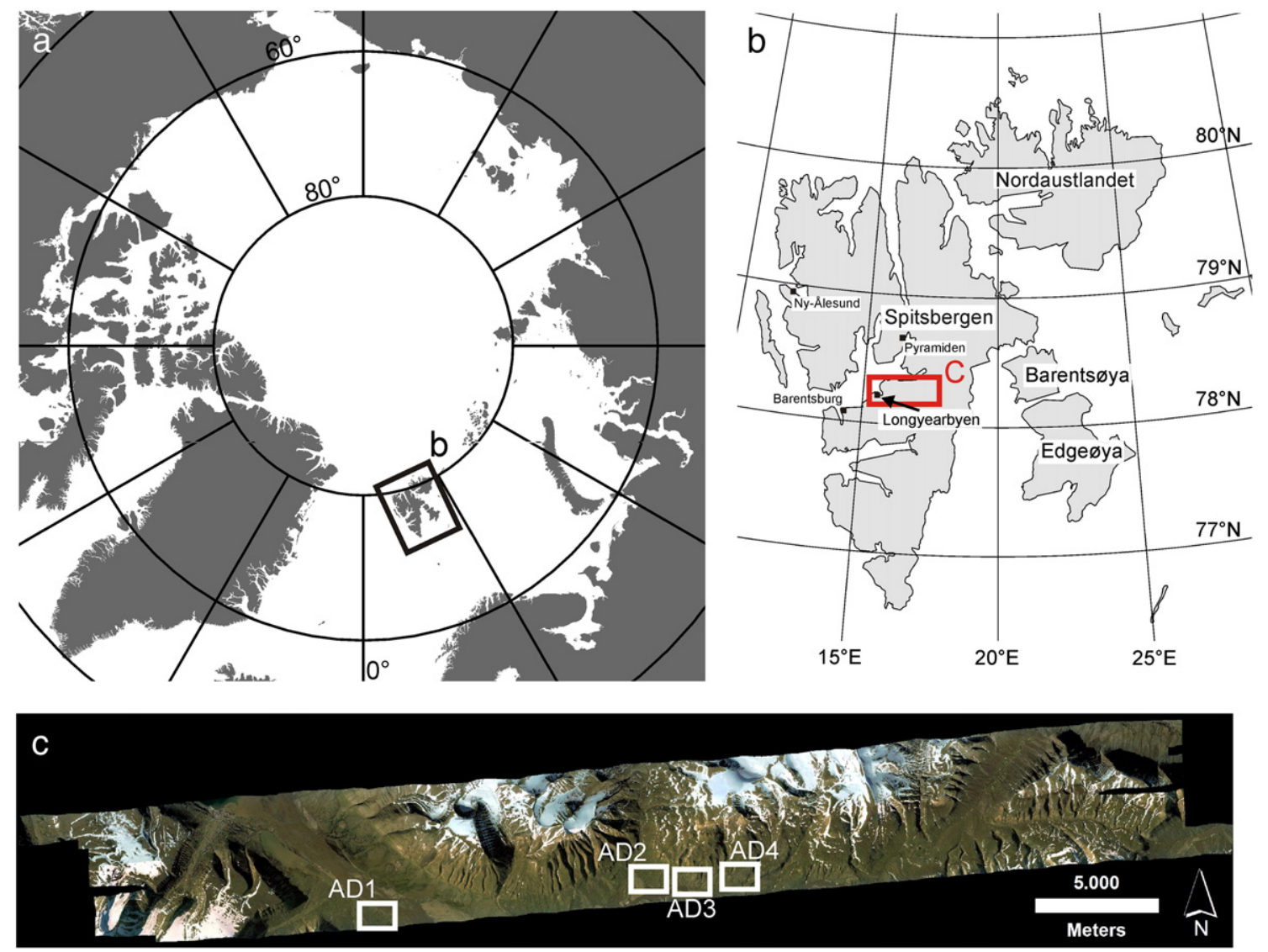

Fig. 1. Context maps of the terrestrial study area. (a) Location of the Svalbard archipelago in the Arctic. (b) Map of Svalbard and its largest island Spitsbergen with the Adventdalen area marked by the black box. (c) HRSC-AX true-color image mosaic of the Adventdalen region with the location of the investigated polygonal fields shown. Elevation increases from site AD1 to site AD4. 

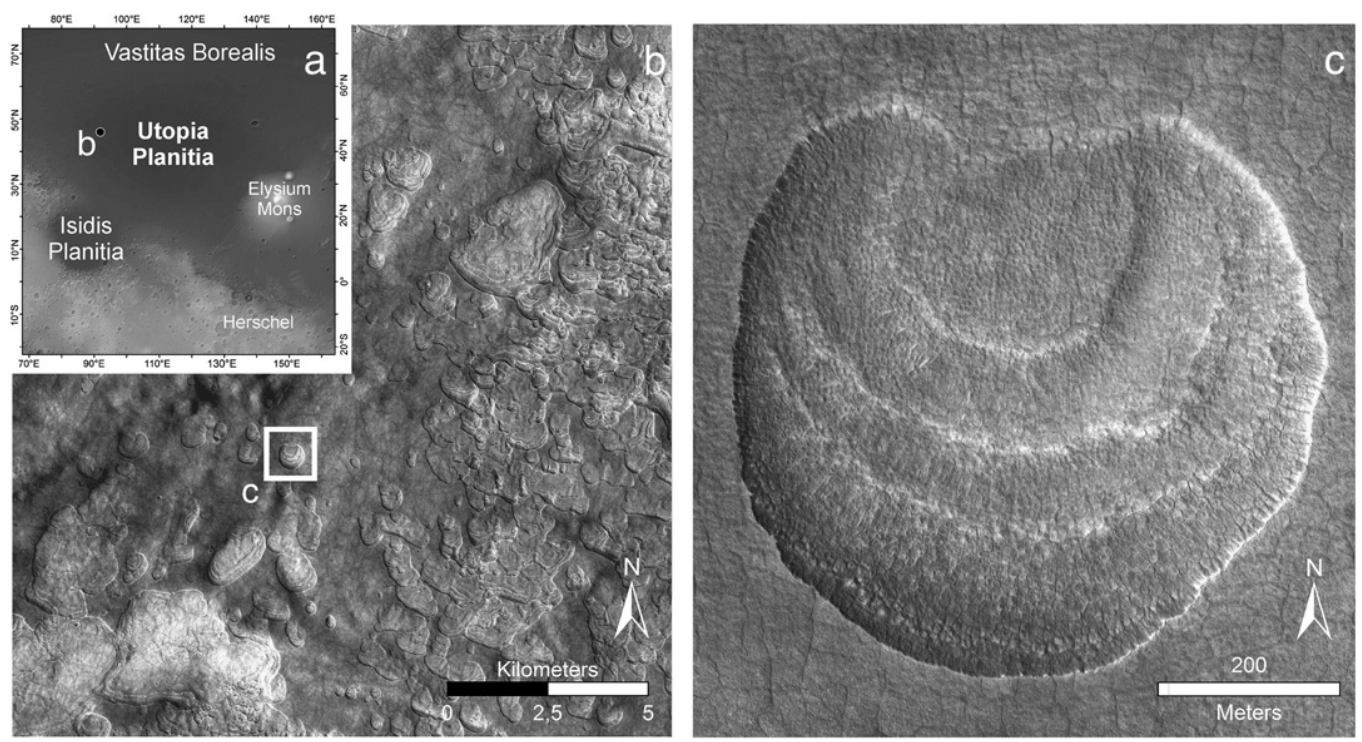

Fig. 2. Regional setting of the Martian study site. (a) Location of Utopia Planitia on the Martian northern hemisphere. (b) Investigated area in western Utopia Planitia. The region is characterized by single scalloped depressions and extended areas of coalesced scalloped terrain (CTX image subset: P02_001938_2263_XI_46N267W). (c) The scalloped depression and the associated polygonal structures on which this study is focused. The depression is characterized by a gentle south-facing slope and a steep north-facing scarp. Four elongated ridges within the depression are oriented subparallel to the north-facing slope. (HiRISE image subset: PSP_001938_2265, see also Fig. 13b of Ulrich et al., 2010).

units: the Vastitas Borealis interior unit $\left(\mathrm{ABv}_{\mathrm{i}}\right)$, which underlies the Astapus Colles unit ( $\mathrm{ABa}$ ) (Tanaka et al., 2005). The ABa unit is interpreted as a fine-grained volatile-rich (i.e., ice-rich) mantling layer tens of meters thick which was deposited during recent variations in Mars' orbital parameters (i.e., higher obliquity) (e.g., Kreslavsky and Head, 2000, 2002; Mustard et al., 2001; Head et al., 2003). The older $\mathrm{ABv}_{\mathrm{i}}$ unit consists mainly of outflow channel sediments and subsequently reworked ice-rich deposits (Tanaka et al., 2005).

Generally, the region is characterized by a relatively smooth and flat surface. The most conspicuous landforms in western UP are asymmetrically-shaped scalloped depressions, which are interpreted as ground ice degradation features (e.g., Morgenstern et al., 2007; Lefort et al., 2009; Ulrich et al., 2010; Séjourné et al., 2011). Isolated depressions (a few hundred meters to several kilometers in diameter) alternate with coalesced scalloped terrain and nested areas of completely removed mantel material (Fig. $2 \mathrm{~b}$ ). About $24 \%$ of this region is covered by scalloped terrain (Morgenstern et al., 2007). Polygonal patterned ground is widespread in western UP (e.g., Seibert and Kargel, 2001; Lefort et al., 2009; Levy et al., 2009b). Small highand low-centered polygons (about $10 \mathrm{~m}$ in diameter) are associated with the scalloped depressions, showing an internal arrangement that is typical of all well-pronounced scalloped depressions. Large polygons (up to $80 \mathrm{~m}$ in diameter) are distributed on the non-degraded plain uplands.

In this work, we focused on four different polygon fields (named UP1 to UP4), which are located in and around a medium-sized scalloped depression (Fig. 2c). This depression is about $800 \mathrm{~m}$ in diameter and $20 \mathrm{~m}$ deep, centered at $\sim 92.12^{\circ} \mathrm{N}$ and $\sim 46.07^{\circ} \mathrm{E}$.

\section{Methods and data}

\subsection{Field work and laboratory analyses}

Field work on Svalbard was conducted by making measurements and observations of various periglacial landforms, analyzing soil properties, and collecting soil samples during July-August 2009 (see also Hauber et al., 2011, in press). The observed and measured parameters are used as a ground-truth dataset for remote-sensing analyses. In total, nine soil profiles were described and sampled at different polygon fields in the Adventdalen. At each site, active-layer samples were taken from centers and troughs of randomly-selected polygons. In situ measurements of active-layer thermal properties were done using a KD2 Pro Thermal Properties Analyzer (Decagon Devices Inc.), and soil water content was measured using a Hydrosense probe (Campbell Scientific Inc.). At site AD1, sediment samples from a polygon center (Fig. 1) taken by Härtel et al. (2010) were also used in order to complete the dataset for sedimentological analyses.

Grain-size analyses were carried out using a Laser Particle Analyzer (Beckmann Coulter LS 200) for the fine fraction $(<1 \mathrm{~mm})$. The coarse fraction $(>1 \mathrm{~mm})$ was sieved additionally with an ATM sonic sifter separator (ATM Corporation, Milwaukee, WIS). Total carbon (TC), total organic carbon (TOC), and total nitrogen (TN) contents were determined with a CNS-Analyzer (Elementar Vario EL III).

\subsection{Remote sensing data}

Very-high-resolution images and topographic information about periglacial landforms on Svalbard were acquired in July and August 2008 with HRSC-AX, which is an airborne version of the HRSC (High Resolution Stereo Camera) currently orbiting Mars (Jaumann et al., 2007). Color orthoimages ( $20 \mathrm{~cm} \mathrm{pixel}^{-1}$ ) and corresponding Digital Elevation Models (DEMs) with a cell size of $50 \mathrm{~cm}$ and a vertical accuracy of $20 \mathrm{~cm}$ are available for seven regions on Svalbard (Hauber et al., 2011, in press). HRSC-AX data from Central Svalbard were used for quantitative terrain and remote-sensing analyses. HRSC-AX is a multi-sensor push-broom instrument with nine CCD line sensors mounted in parallel. High-resolution stereo, multicolor, and multiphase images are obtained simultaneously. True-color and false-color orthoimages are obtained from the four-band data (blue, green, red, and near-infrared). Based on the five stereo channels, which provide five different views of the ground, digital photogrammetric techniques are applied to reconstruct the topography. The stereo capability of the HRSC-AX allows the systematic production of highresolution DEMs. The principles of HRSC data processing and application are described by e.g., Wewel et al. (2000), Scholten et al. (2005), and Gwinner et al. (2009, 2010).

Martian polygonal structures were analyzed using High-Resolution Imaging Science Experiment (HiRISE) data (McEwen et al., 2007). HiRISE provides data that have a quality and scale comparable to HRSC-AX, with a very high spatial resolution of $30 \mathrm{~cm}_{\text {pixel }}^{-1}$ and the possibility of 3D views by stereo pairs. The method of producing high-resolution DEMs based on stereo pairs is available (Kirk et al., 2008). However, detailed 
analyses, mapping, and extraction of geomorphometric parameters were restricted to the stereo pair PSP_001938_2265 and PSP_002439_2265 and the corresponding DEM with a grid spacing of $1 \mathrm{~m}$. To our knowledge, this is the only HiRISE DEM covering scalloped terrain and related polygonal structures in UP, because HiRISE stereo pairs cover only very small parts of the Martian surface and are very difficult to process (Kirk et al., 2008; McEwen et al., 2010).

\subsection{GIS analysis and polygon mapping}

Polygons were manually digitized within $\operatorname{ArcGIS}^{\mathrm{TM}}$ from panchromatic HiRISE and HRSC-AX data using the corresponding DEMs and DEMderived slope maps as well as 3D views (i.e., in case of the HiRISE data) for better visualizing polygon edges, fissures, troughs, and intersections. Only clearly-recognizable polygon fissures and troughs which could be reliably interpreted as non-erosional linear structures have been mapped along the centerline (Fig. 3). In the case of the terrestrial high-centered polygons, the polygon interiors were also mapped along the highest points of the trough shoulders. The distance from each polygon trough shoulder to the shoulder edge of its nearest neighbor was then calculated automatically in $\operatorname{ArcGIS}^{\mathrm{TM}}$, allowing estimates of minimum polygon trough widths at each site. Furthermore, locations where two polygon-bounding troughs intersect were marked with points and the distributions of four- and three-ray intersections were distinguished (Fig. 3). Theoretically, a polygonal field which is characterized by a higher frequency of connected four-ray intersections could be specified as an orthogonal polygon pattern even if the polygon geometry was primarily determined by the conjunction angle (e.g., Lachenbruch, 1962; French, 2007). A polygon was considered in the dataset if it was completely enclosed by troughs or cracks and if there was no doubt during mapping as to whether the visible lineaments corresponded to the original polygon form. Problems appear, for instance, at degraded surfaces, or where slope deposits are superimposed upon troughs. In those cases, the original polygon geometry was often difficult to identify precisely despite the high image resolution.

For each recorded polygon, geomorphometric parameters (Fig. 3) and topographical properties were extracted within ArcGIS ${ }^{\mathrm{TM}}$ and added to

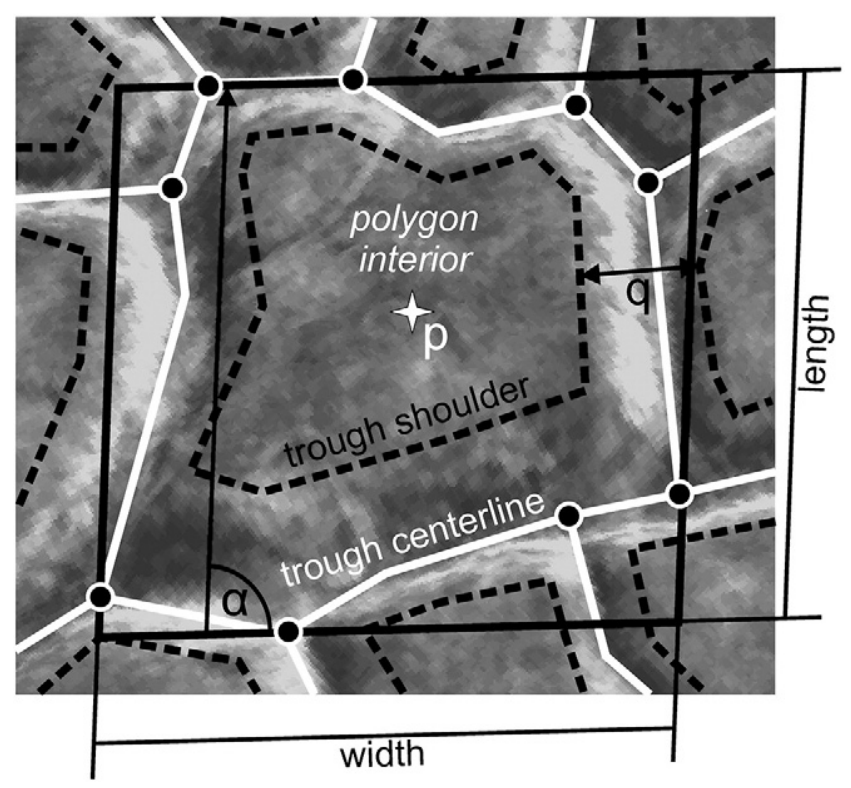

Fig. 3. Scheme of extracted geomorphometric parameters using the example of a highcentered polygon in the Adventdalen. Based on those characteristics, additional parameters could be calculated (see also Table 2). The centerline (i.e., the cracks that outline the low-centered polygons) surrounds the area. The length of the centerline represents the perimeter. Trough intersections are illustrated by the black dots. (p) Polygon center point, (q) calculated minimum polygon trough width, $(\alpha)$ polygon main angle (i.e., direction of polygon elongation). Oblique 3-D view based on HRSC-AX topography data. an attribute table. Dimension parameters include area $(A)$, perimeter $(P)$, length $(L)$, width $(W)$, and size $(S)$ (Table 2 ). $S$ was calculated as equivalent to the diameter (Yoshikawa, 2003). Three shape factors were calculated, including circularity $(F F)$, aspect ratio $(A R)$, and thickness ratio $(T h)$ (Table 2). All shape factors have values between 0 and 1 . The smaller the value, the thinner (i.e., more elongated) is the polygon. Topographical properties (i.e., elevation, slope angle, and slope aspect) were extracted for the center point of each polygon after smoothing the HiRISE DEM and the HRSC-AX DEM to $10 \mathrm{~m}_{\text {pixel }}^{-1}$, taking into account small-scale changes in topography. Moreover, to investigate the relationship of the slope direction to the orientation of polygon elongation, the main angle of the longest axis of a minimum-area-bounding rectangle was calculated for each polygon, which is at least $15 \%$ longer than broader. This bounding rectangle schematically represents the original orientation of polygon elongation (Fig. 3). Fairly-symmetrical polygons which are not $15 \%$ longer than they are broad were not considered. Calculated angles range between $0^{\circ}$ and $180^{\circ}$, where $0^{\circ}$ corresponds to a polygon directed from east to west, $90^{\circ}$ corresponds to a north-south direction, and $180^{\circ}$ represents a west-to-east direction. Therefore, the slope aspect, represented by values ranging between $0^{\circ}$ and $360^{\circ}$, was converted to values ranging between $0^{\circ}$ and $180^{\circ}$, and thereafter represents the direction of slope angle.

\subsection{Numerical analyses}

Multivariate statistics in terms of ordination methods were applied to the remote-sensing datasets from Spitsbergen and Mars. First, principal component analyses (PCAs) were performed to assess the relationships among the polygon shape and the dimensional variables (Table 2). Second, redundancy analyses (RDAs, partialRDAs) including environmental parameters as explanatory variables (Table 2) were applied to identify factors that could significantly explain variations in polygon shape and dimension. In preparation for the multivariate analyses, datasets were organized for each polygon site that contained all the studied polygons, dimension parameters,

Table 2

Geomorphometric parameters and topographical properties which were extracted and calculated for each considered polygon and used as variables in multivariate statistics. See also Fig. 3.

\begin{tabular}{|c|c|c|c|}
\hline $\begin{array}{l}\text { Variable } \\
\text { (abbreviation) }\end{array}$ & $\begin{array}{l}\text { Unit or } \\
\text { scale }\end{array}$ & Source (explanation) & Type \\
\hline \multicolumn{4}{|c|}{ Response variables } \\
\hline Area $(A)$ & $\begin{array}{l}\text { Square } \\
\text { meter }\end{array}$ & HRSC-AX, HiRISE & Dimension \\
\hline Perimeter $(P)$ & Meter & HRSC-AX, HiRISE & Dimension \\
\hline Size $(S)$ & Meter & $=\sqrt{(4 A / \pi)}$ & Dimension \\
\hline Length $(L)$ & Meter & $\begin{array}{l}\text { HRSC-AX, HiRISE } \\
\text { (largest diameter) }\end{array}$ & Dimension \\
\hline Width $(W)$ & Meter & $\begin{array}{l}\text { HRSC-AX, HiRISE } \\
\text { (smallest diameter) }\end{array}$ & Dimension \\
\hline $\begin{array}{l}\text { Circularity } \\
(F F)\end{array}$ & 0 to 1 & $=4 \pi A / P^{2}$ & Shape \\
\hline $\begin{array}{l}\text { Aspect ratio } \\
\qquad(A R)\end{array}$ & 0 to 1 & $=W / L$ & Shape \\
\hline $\begin{array}{l}\text { Thickness } \\
\text { ratio }(T h)\end{array}$ & 0 to 1 & $\begin{array}{l}=\text { The polygon area versus the } \\
\text { area of its minimum bounding } \\
\text { rectangle }\end{array}$ & Shape \\
\hline CosMA & -1 to 1 & $\begin{array}{l}=\text { Cosine representation of } \\
\text { polygon main angle values }\end{array}$ & $\begin{array}{l}\text { Orientation of } \\
\text { polygon } \\
\text { elongation }\end{array}$ \\
\hline \multicolumn{4}{|c|}{ Explanatory variables } \\
\hline $\begin{array}{l}\text { Relative } \\
\text { height }(R H)\end{array}$ & $\begin{array}{l}\text { Meter } \\
\text { (above } \\
\text { fixed point) }\end{array}$ & DEM & Topography \\
\hline Slope (Slo) & Degrees & DEM & Topography \\
\hline $\begin{array}{l}\text { Northness } \\
\quad(\mathrm{No})\end{array}$ & -1 to 1 & $=\cos$ (Aspect), DEM & Topography \\
\hline Eastness $(E a)$ & -1 to 1 & $=\sin ($ Aspect), DEM & Topography \\
\hline
\end{tabular}


shape factors, and polygon main angles as response variables as well as topographical properties as environmental (i.e., explanatory) variables (Table 2). First, a data exploration was carried out to check the data distribution and relationships between the variables, and to calculate the statistical characters, such as mean, median, maximum (Max), and minimum (Min) values, or standard deviation (SD) and skewness (SK) for comparing of the different polygon sites. Circular data, such as aspect and polygon main angle, were transformed by trigonometric functions (e.g., Roberts, 1986) (Table 2). Aspect transformation was accomplished by creating two variables, northness $(\mathrm{No})$ and eastness $(\mathrm{Ea})$. Polygon main angle values $\left(0-180^{\circ}\right)$ were transformed to cosine representation (CosMA), ranging thus from 1 to -1 . Elevation is represented by the relative height $(R H)$; the lowest-level polygon within each polygon site was set to $R H=0$.

PCA and RDA were performed on standardized data (i.e., all variables have equal weights) using BRODGAR version 2.6.5. (Highland Statistics Ltd., UK). These ordination techniques are commonly used in ecological data analysis (Zuur et al., 2007). PCA is a comparatively simple method used to visualize correlations between variables. RDA is an extension of the PCA; it models the response variables as a function of the explanatory variables. The ordination axes and algorithm in RDA are based on the PCA.

Ecological data which originate from neighboring objects in the same physical environment are often spatially autocorrelated, because the objects interact and are often more alike than objects which are far apart from each other. Spatial autocorrelation within our dataset, which could result in a lack of stochastic independence, was addressed using principal coordinates of neighbor matrices (PCNM) analyses (Borcard and Legendre, 2002; Borcard et al., 2004). This method allows spatial patterns to be detected and quantified over a wide range of scale by creating spatial variables. Using the Cartesian coordinates $(x, y)$ of each polygon center, a set of spatial variables was generated for each polygon site. These analyses yielded up to 400 PCNM variables per site. To assess the amount of variance that is explained by the "pure" non-spatiallystructured environmental variables, the effect of the spatial variables could then be partialled out by the use of variance partitioning through partial-RDA for each polygon dataset (e.g., Borcard et al., 1992; Zuur et al., 2007; Sweetman et al., 2010). First, a series of RDAs were run constrained to each spatial and environmental variable. Only variables which explained a significant ( $p$-value $<0.05$ ) amount of variance in the polygon dataset were considered for further analyses. The statistical significance was tested continually by Monte Carlo permutation tests using 999 unrestricted permutations. Thereafter, we applied a separate RDA with a forward-selection procedure for all significant spatial and environmental variables to identify the most important variables that could ultimately explain variations in polygon dimension and shape among sites. Collinearity among the variables could be excluded, as all the highest variance inflation factors (VIFs) were $<5$. Finally, variance partitioning in a series of partial RDAs was conducted for each polygon site: i) on all forward-selected spatial and all forward-selected environmental variables; ii) on all forward-selected spatial variables, using the forward-selected environmental variables as covariables; and iii) on all forward-selected environmental variables, using the forwardselected spatial variables as covariables. The amount of variance in each polygonal network that is explained by the effect of the pure environmental variables, that of the pure spatial variables, the shared effect, and the amount of unexplained variance could then be determined using the cumulative eigenvalues as the percentage of total inertia (i.e., variance) explained by each of these calculations.

\section{Results}

\subsection{Geomorphology and morphometry of Adventdalen polygons}

Four polygonal fields were mapped with a total of 688 polygons (Fig. 4 and Table 3). These fields are distinguishable with respect to their dimensions, geomorphology, and the associated surficial material. For each polygonal site, the characteristics of geomorphometric parameters are summarized in Table 4.

Site AD1 is located on the front of a recently inactive alluvial fan, which is cut by the Adventelva River. The area is exposed generally in a north-northeastern direction (Fig. 4). The polygonal field is formed in eolian deposits (Tolgensbakk et al., 2001), which cover this part of the fan and is characterized by some orthogonal but mostly pentagonal and hexagonal low-centered polygons (Fig. 5). Nearly $90 \%$ of the counted furrow intersections belong to the three-ray type (Table 3). The polygons are outlined by comparatively shallow ( $<40 \mathrm{~cm}$ deep) and narrow ( $<100 \mathrm{~cm}$ wide) furrows. Typically, the low-centered polygons are characterized by pairs of slightly-raised rims beside the furrows. Open cracks could be observed within the furrows during field work. Sizes of individual polygons range from 8.1 to $50.8 \mathrm{~m}$ (mean $19.7 \mathrm{~m}$ ). A shift to smaller dimensions can be seen in positive $S K$ of the dimension variables (Table 4 ). The vegetation cover shows a zonal distribution, with grasses and mosses in less-well drained centers. Dry and sparse vegetation covers the raised rims. However, not all of the mapped polygons are characterized by distinct low-lying centers. In these cases, the center can be described as rather flat, and the drainage situation is improved.

The AD2 polygonal field formed in glaciofluvial sediments (Tolgensbakk et al., 2001). Its high-centered polygons are located on a terraced gentle slope (mean slope angle $=3^{\circ}$ ), which is exposed in a south-southwest direction (Fig. 4). The upper slope and the terrace transitions show steeper slope angles (up to 9). Polygon sizes range from 9.4 to $65.1 \mathrm{~m}$ (mean $29.7 \mathrm{~m}$ ) (Table 4). Bigger polygons occur on gentle slope sections and smaller polygons on the steeper parts (Fig. 5). In general, the polygonal field shows a pentagonal to hexagonal lattice. Only $4 \%$ of the mapped intersections belong to the four-ray type, which is the lowest percentage of this type of all mapped polygon sites (Table 3). The majority of polygonal troughs at site AD2 are less pronounced than at sites AD3 and AD4, especially in gentler, lower slope sections. The mean of the calculated minimum trough widths is $1.4 \mathrm{~m}$, but the width can reach maxima of $4.2 \mathrm{~m}$. Trough depths of $0.5 \mathrm{~m}$ on average were measured in the HRSC-AX DEM. Depths of more than $1 \mathrm{~m}$ could be observed in the field on steeper slope sections. Upon visual inspection of the DEM, polygons that appear bigger seem to be clearly elongated parallel to the slope contour and exist primarily in the lower slope sections (Fig. 4). The calculated shape variables for site AD2 cannot be differentiated clearly from those of the other Adventdalen sites apart from a slightly larger variance of the values (Table 4). The vegetation cover at site AD2 is more or less closed but thins out up the slope and on exposed lower slope parts. The well-drained elevated polygon centers show hummocks covered by dry grasses, herbs, and shrubs, while grasses, mosses, and shrubs in the troughs appear to be more succulent. The shoulders of big troughs are often disrupted and only sparsely vegetated.

According to Tolgensbakk et al. (2001), the AD3 polygonal field is spread on solifluction and autochthonous weathered material. The mean size of the high-centered polygons is $25.4 \mathrm{~m}$ (ranging from 10.4 to $51.7 \mathrm{~m}$ ) (4). About $93 \%$ of all observed intersections belong to the three-ray type. This site is also located on a terraced slope. However, the southerly exposed slope is partly steeper (mean slope angle $=4.9^{\circ}$ ) than the slope at site AD2. It rises shortly and sharply from the Adventelva River, and it is more frequently incised by fluvial channels (Fig. 4). The polygonal field is cut by the river as well. A general trend in the distribution of larger polygons as a function of steeper slope sections could not be observed. Polygons at this site are rather regularly distributed with respect to their dimension and shape. The troughs, however, are more pronounced. The mean of the calculated minimum width at site AD3 is $2.3 \mathrm{~m}$, ranging to maxima of $4.6 \mathrm{~m}$ (Table 3 ). Most of the measured trough depths ranged between 0.3 and $>1 \mathrm{~m}$; the deeper troughs drain into the fluvial channels. 

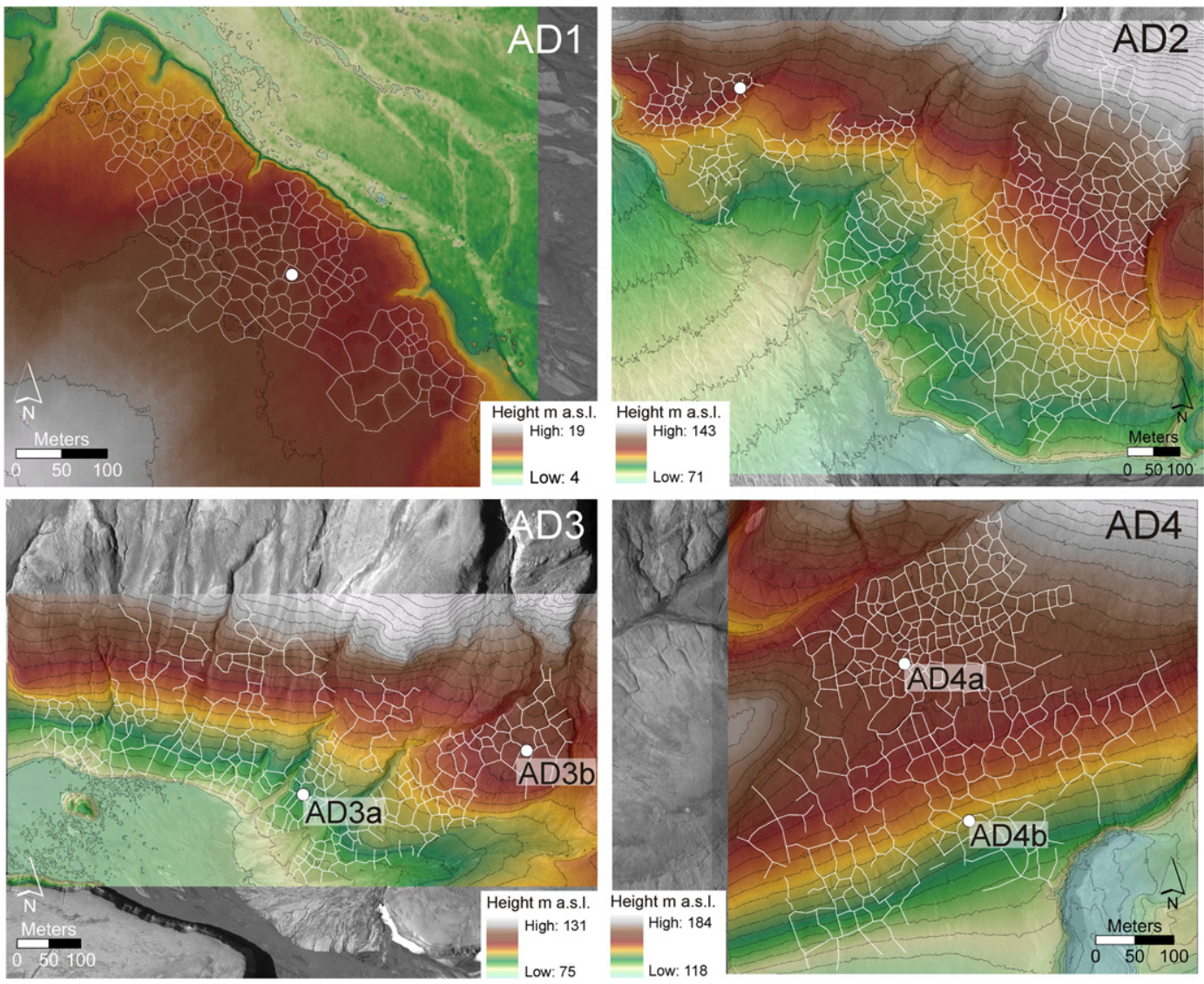

Fig. 4. Mapped polygonal fields in the Adventdalen (Svalbard). HRSC-AX DEM subsets on panchromatic HRSC-AX images illustrate the topography at each site. Contours are given by the gray lines at $2 \mathrm{~m}$ intervals. The white dots mark the location of the investigated active-layer profiles. Profiles of diverse polygons at one site are labeled additionally (see Fig. 7).

Trough shoulders are disrupted by trough-parallel fractures (Fig. 5). The site is characterized by generally drier surface conditions, but these change sharply in the eastern part and in the up-slope direction. The relatively closed but low-standing vegetation cover on the elevated polygon centers changes to exposed vegetation-free areas; only low grasses and dry mosses can be found in the polygon troughs.

AD4, the most elevated polygonal field (Fig. 4) in the Adventdalen (between 139 and $169 \mathrm{~m}$ a.s.l.), is formed in autochthonous weathering material (Tolgensbakk et al., 2001) and characterized by remarkably

Table 3

Overview and characteristics of all mapped polygonal sites and corresponding trough intersections.

\begin{tabular}{|c|c|c|c|c|c|c|c|}
\hline Location & ID & Type & $\mathrm{N}$ & $\begin{array}{l}\text { Covered area } \\
\left(\times 10^{3} \mathrm{~m}^{2}\right)\end{array}$ & $\begin{array}{l}\text { Trough } \\
\text { intersections }\end{array}$ & $\begin{array}{l}\text { 3-ray } \\
\text { (\%) }\end{array}$ & $\begin{array}{l}\text { 4-ray } \\
(\%)\end{array}$ \\
\hline Adventdalen & AD1 & $\begin{array}{l}\text { Low } \\
\text { center }\end{array}$ & 185 & 63 & 387 & 90.2 & 9.8 \\
\hline Adventdalen & AD2 & $\begin{array}{l}\text { High } \\
\text { center }\end{array}$ & 241 & 186 & 698 & 96.0 & 4.0 \\
\hline Adventdalen & AD3 & $\begin{array}{l}\text { High } \\
\text { center }\end{array}$ & 103 & 58 & 381 & 92.9 & 7.1 \\
\hline Adventdalen & AD4 & $\begin{array}{l}\text { High } \\
\text { center }\end{array}$ & 159 & 80 & 426 & 91.3 & 8.7 \\
\hline $\mathrm{AD}$ total & & & 688 & 387 & 1892 & & \\
\hline $\begin{array}{l}\text { Utopia } \\
\text { Planitia }\end{array}$ & UP1 & $\begin{array}{l}\text { High } \\
\text { center }\end{array}$ & 453 & 477 & 1293 & 92.4 & 7.6 \\
\hline $\begin{array}{l}\text { Utopia } \\
\text { Planitia }\end{array}$ & UP2 & $\begin{array}{l}\text { Low } \\
\text { center }\end{array}$ & 756 & 58 & 1751 & 82.9 & 17.1 \\
\hline $\begin{array}{l}\text { Utopia } \\
\text { Planitia }\end{array}$ & UP3 & $\begin{array}{l}\text { High } \\
\text { center }\end{array}$ & 579 & 63 & 1562 & 86.4 & 13.6 \\
\hline $\begin{array}{l}\text { Utopia } \\
\text { Planitia }\end{array}$ & UP4 & $\begin{array}{l}\text { Low } \\
\text { center }\end{array}$ & 566 & 30 & 1110 & 87.4 & 12.6 \\
\hline UP total & & & 2354 & 628 & 5716 & & \\
\hline Total & & & 3042 & 1015 & 7608 & & \\
\hline
\end{tabular}

wide and deep troughs and very sparse vegetation cover (Fig. 5). The mean of the calculated minimum trough width is $2.9 \mathrm{~m}$, but widths range to maxima of $7.5 \mathrm{~m}$. The manually-measured depth of the troughs is between 0.5 and $>1 \mathrm{~m}$. The size of the high-centered polygons ranges between 9.8 and $47.7 \mathrm{~m}$ (mean $24.2 \mathrm{~m}$ ) (Table 4). Smaller, rather hexagonal polygons are located on an elevated terrace, which is characterized by a very dry surface (Fig. 5). Secondary cracks can be observed within the polygon centers. They were probably formed by desiccation when the surface dried after spring snowmelt. The terrace continues on a south-southeast exposed slope which is inclined toward the Adventelva River. The mean slope angle is $3.5^{\circ}$ but can reach about $10^{\circ}$ in the lower slope sections. Down the slope, vegetation cover becomes denser and polygon dimensions increase. Here the polygons show an orthogonal lattice in some places. About $9 \%$ of all polygon intersections at site AD4 belong to the four-ray type (Table 3).

All high-centered polygonal fields are located on inclined surfaces. We found a small but significant correlation $(r=0.32 ; p$-value $<0.05)$ between minimum polygon trough width and slope angle for all Adventdalen high-centered polygons. At all Adventdalen sites polygons are elongated in two main directions, subparallel to the contour of the slope and subparallel to the direction of slope angle (Fig. 6). The majority of polygons at site AD1 are elongated perpendicularly to the direction of slope angle. The majority of polygons at site $\mathrm{AD} 3$ and in particular at $\mathrm{AD} 4$ are predominantly elongated subparallel to the slope angle direction. For site AD2, a relative balance of orientation is shown in Fig. 6 in contrast to the visual observations (see above, Fig. 4).

\subsection{Sedimentology of the Adventdalen polygons}

The sedimentological results for ten active-layer profiles of individual polygons representative of each polygonal field are summarized in Fig. 7. Sediment data are presented for the trough 
Table 4

Calculated statistical characteristics of the geomorphometric parameters for each polygonal field in the Adventdalen (AD) and Utopia Planitia (UP). (Units and scales correspond to Table 2).

\begin{tabular}{|c|c|c|c|c|c|c|c|c|c|}
\hline & & AD1 & AD2 & AD3 & $\mathrm{AD} 4$ & UP1 & UP2 & UP3 & UP4 \\
\hline \multirow[t]{6}{*}{ Area } & Min & 50.9 & 69.7 & 84.9 & 75.1 & 135.6 & 15.6 & 14.7 & 10.0 \\
\hline & Max & 2029.0 & 3328.6 & 2100.5 & 1785.7 & 6098.7 & 206.6 & 513.0 & 151.9 \\
\hline & Mean & 340.1 & 771.1 & 558.5 & 506.7 & 1053.4 & 76.7 & 109.2 & 52.4 \\
\hline & Median & 268.4 & 594.3 & 447.2 & 82.7 & 816.1 & 69.5 & 91.6 & 50.1 \\
\hline & SD & 261.6 & 534.7 & 378.2 & 331.0 & 830.3 & 35.5 & 65.2 & 18.4 \\
\hline & SK & 3.0 & 1.7 & 1.7 & 1.3 & 2.1 & 1.0 & 1.9 & 1.4 \\
\hline \multirow{6}{*}{ Perimeter } & Min & 30.4 & 35.2 & 39.9 & 37.2 & 46.8 & 16.3 & 16.6 & 13.2 \\
\hline & Max & 177.1 & 245.5 & 170.7 & 178.1 & 298.4 & 59.8 & 92.9 & 51.2 \\
\hline & Mean & 69.8 & 108.3 & 90.8 & 87.1 & 124.2 & 34.4 & 40.5 & 28.7 \\
\hline & Median & 65.0 & 100.5 & 87.2 & 82.7 & 117.9 & 33.6 & 38.9 & 28.2 \\
\hline & $\mathrm{SD}$ & 23.8 & 38.3 & 28.3 & 28.6 & 46.5 & 7.8 & 11.1 & 5.3 \\
\hline & SK & 1.6 & 0.8 & 0.9 & 0.7 & 0.9 & 0.5 & 1.0 & 1.0 \\
\hline \multirow[t]{6}{*}{ Size } & Min & 8.1 & 9.4 & 10.4 & 9.8 & 13.1 & 4.5 & 4.3 & 3.6 \\
\hline & Max & 50.8 & 65.1 & 51.7 & 47.7 & 88.1 & 16.2 & 25.6 & 13.9 \\
\hline & Mean & 19.7 & 29.7 & 25.4 & 24.2 & 34.3 & 9.6 & 11.4 & 8.1 \\
\hline & Median & 18.5 & 27.5 & 23.9 & 23.5 & 32.2 & 9.4 & 10.8 & 8.0 \\
\hline & SD & 6.6 & 10.0 & 8.2 & 7.8 & 12.8 & 2.2 & 3.2 & 1.4 \\
\hline & SK & 1.5 & 0.7 & 0.9 & 0.6 & 0.9 & 0.5 & 0.9 & 0.5 \\
\hline \multirow[t]{6}{*}{ Length } & Min & 11.4 & 13.3 & 14.8 & 13.4 & 18.8 & 6.4 & 6.1 & 5.1 \\
\hline & Max & 65.3 & 96.2 & 61.7 & 71.3 & 109.4 & 24.5 & 35.7 & 22.6 \\
\hline & Mean & 25.6 & 40.9 & 33.5 & 32.3 & 46.2 & 12.9 & 15.1 & 10.7 \\
\hline & Median & 24.2 & 37.4 & 31.7 & 30.3 & 43.8 & 12.3 & 14.7 & 10.3 \\
\hline & SD & 9.0 & 14.9 & 10.1 & 10.7 & 16.9 & 3.0 & 4.1 & 2.2 \\
\hline & SK & 1.6 & 1.2 & 0.8 & 0.8 & 0.8 & 0.8 & 1.0 & 1.4 \\
\hline \multirow[t]{6}{*}{ Width } & Min & 7.0 & 10.2 & 9.6 & 9.9 & 12.3 & 4.1 & 4.2 & 3.8 \\
\hline & Max & 49.8 & 79.4 & 51.4 & 57.0 & 82.7 & 18.2 & 27.9 & 13.1 \\
\hline & Mean & 19.9 & 28.7 & 25.1 & 24.6 & 35.0 & 10.0 & 11.6 & 8.1 \\
\hline & Median & 18.6 & 27.2 & 23.4 & 23.8 & 33.4 & 9.9 & 11.1 & 8.0 \\
\hline & SD & 6.7 & 10.3 & 8.4 & 8.0 & 13.6 & 2.4 & 3.6 & 1.4 \\
\hline & SK & 1.5 & 1.2 & 0.9 & 0.6 & 0.9 & 0.4 & 0.9 & 0.2 \\
\hline \multirow[t]{6}{*}{ Circularity } & Min & 0.58 & 0.47 & 0.57 & 0.58 & 0.41 & 0.41 & 0.21 & 0.46 \\
\hline & Max & 0.91 & 0.91 & 0.91 & 0.92 & 0.92 & 0.92 & 0.92 & 0.92 \\
\hline & Mean & 0.79 & 0.75 & 0.77 & 0.76 & 0.76 & 0.78 & 0.78 & 0.78 \\
\hline & Median & 0.81 & 0.76 & 0.78 & 0.77 & 0.76 & 0.78 & 0.79 & 0.80 \\
\hline & $\mathrm{SD}$ & 0.06 & 0.08 & 0.08 & 0.07 & 0.08 & 0.07 & 0.08 & 0.08 \\
\hline & SK & -0.83 & -0.74 & -0.49 & -0.29 & -0.77 & -0.74 & -1.46 & -0.83 \\
\hline \multirow[t]{6}{*}{ Aspect ratio } & Min & 0.41 & 0.37 & 0.45 & 0.46 & 0.37 & 0.35 & 0.37 & 0.37 \\
\hline & Max & 1.00 & 0.99 & 0.98 & 0.99 & 0.99 & 0.99 & 1.00 & 1.00 \\
\hline & Mean & 0.79 & 0.72 & 0.75 & 0.77 & 0.76 & 0.79 & 0.77 & 0.77 \\
\hline & Median & 0.80 & 0.72 & 0.76 & 0.78 & 0.77 & 0.80 & 0.79 & 0.78 \\
\hline & SD & 0.12 & 0.14 & 0.12 & 0.13 & 0.13 & 0.12 & 0.12 & 0.12 \\
\hline & SK & -0.50 & -0.19 & -0.48 & -0.44 & -0.35 & -0.65 & -0.60 & -0.57 \\
\hline \multirow[t]{6}{*}{ Thickness ratio } & Min & 0.29 & 0.24 & 0.30 & 0.26 & 0.29 & 0.23 & 0.15 & 0.27 \\
\hline & Max & 0.76 & 0.84 & 0.70 & 0.80 & 0.85 & 0.88 & 0.86 & 0.79 \\
\hline & Mean & 0.53 & 0.49 & 0.51 & 0.51 & 0.55 & 0.52 & 0.53 & 0.54 \\
\hline & Median & 0.52 & 0.49 & 0.52 & 0.51 & 0.55 & 0.51 & 0.52 & 0.54 \\
\hline & $\mathrm{SD}$ & 0.09 & 0.10 & 0.10 & 0.10 & 0.11 & 0.10 & 0.11 & 0.11 \\
\hline & SK & -0.11 & 0.11 & -0.15 & 0.19 & 0.05 & 0.13 & -0.02 & -0.08 \\
\hline
\end{tabular}

and the center of one polygon at site AD2 and AD4a, respectively (Fig. 4). Due to varying surface conditions down-slope at site AD4 an additional analysis is shown for an active-layer pit in a polygon trough (AD4b). Because of heterogeneous surface conditions at site AD3, the center and trough of two polygons were surveyed. At site AD1, samples from the topmost $100 \mathrm{~cm}$ of an active-layer pit and a permafrost core (Fig. 4) were analyzed to complete the dataset. Field measurements of thermal conductivity and ground temperature were done exemplarily at sites AD2, AD3, and AD4a. These measurements were used additionally to distinguish the various polygon fields as well as the trough and center of separate polygons.

All active-layer profiles are characterized by poorly sorted, clayish to fine-sandy silts with varying amounts of gravel and low TOC values (Fig. 7). The range of the TOC/TN ratios is relatively wide (between 12 and 25). Except for the polygon center pit at site AD1, all profiles were dark-grayish to grayish-black in color and unstratified. No signs of underlying ice wedges could be found at sites AD2, AD3, or AD4. Active-layer depths at all sites ranged between $\sim 60$ and $\sim 100 \mathrm{~cm}$. The deepest active layer of $\sim 100 \mathrm{~cm}$ (Fig. 7) was measured where the vegetation cover was absent and the surface appeared mostly dry. In comparison to the other sites, the AD1 profile shows less clay but higher sand contents corresponding to the mapped loess-like sediments of Tolgensbakk et al. (2001) and the material is better sorted. The AD4b trough profile contains the highest gravel content, particularly at the bottom (Fig. 7). Furthermore, measurable proportions of gravel could be determined for sites AD2 and AD4a, corresponding to the glaciofluvially-formed and autochthonouslyweathered surface material suggested by Tolgensbakk et al. (2001). At site AD2 only, the trough profile reveals considerably higher grain size mean values, corresponding to higher sand contents than in the related polygon center profile (Fig. 7).

The measured thermal properties reflect the sedimentological similarities of the four sites. The temperature decreases to about $0{ }^{\circ} \mathrm{C}$ towards the permafrost table. Thermal conductivity values range around $1.0 \mathrm{Wm}^{-1} \mathrm{~K}^{-1}$ at all sites, increasing slightly with depth, and show higher values (up to $2.6 \mathrm{Wm}^{-1} \mathrm{~K}^{-1}$ ) in the upper centimeters of the permafrost due to the ice content (e.g., the center of AD4a in Fig. 7). The typical relationships of decreasing thermal conductivity with increasing organic carbon content and of increasing thermal conductivity with increasing soil moisture (e.g., Williams and Smith, 1989; Yershov, 2004; French, 2007) are confirmed by our measurements. 

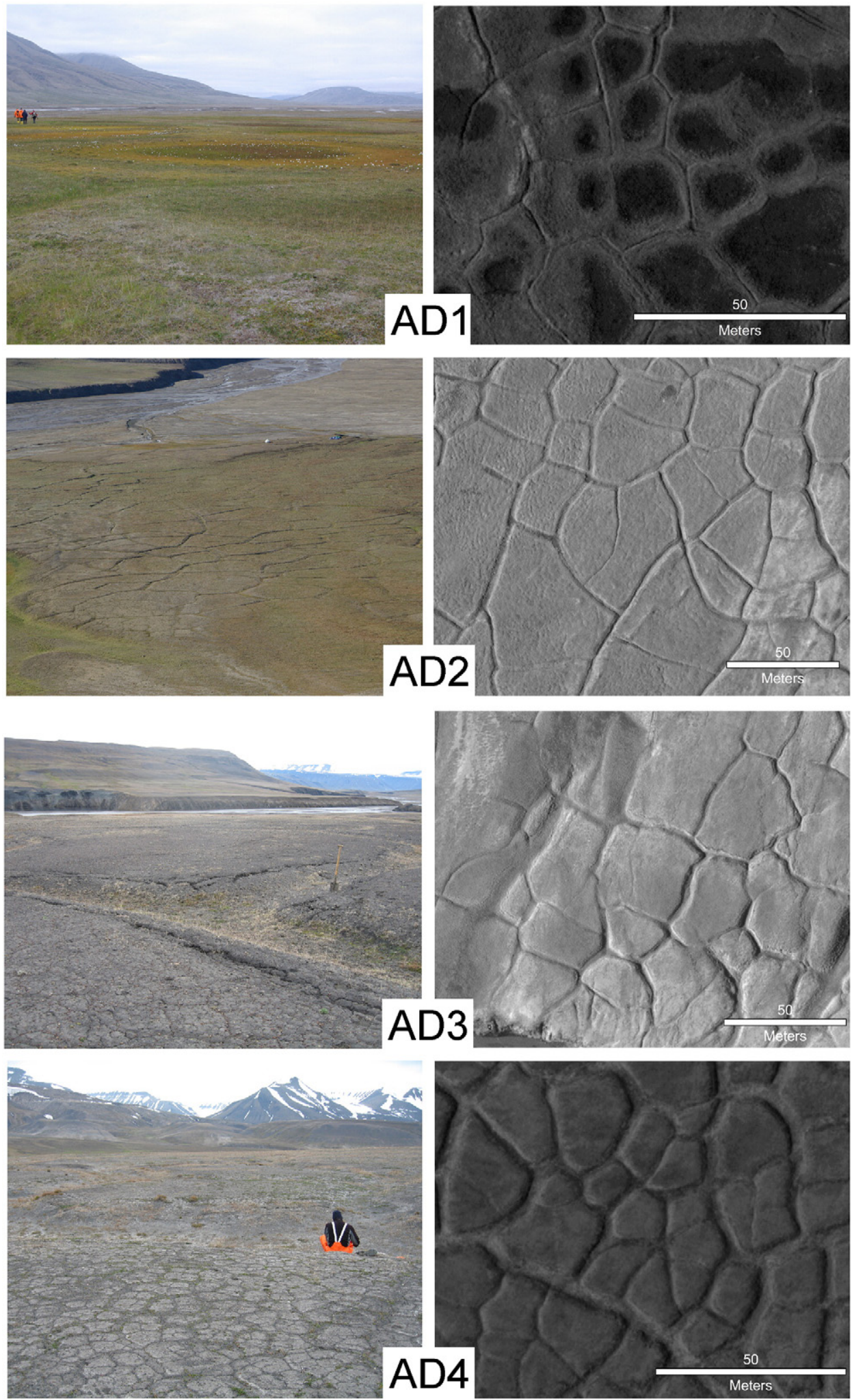

Fig. 5. Photograph and HRSC_AX close-up of each polygonal field in the Adventdalen elucidate the site-specific differences in geomorphology. Low-centered polygons at site AD1 are formed in eolian deposits on an inactive alluvial fan. High-centered polygons at the sites AD2, AD3, and AD4 are formed in glaciofluvial sediments, solifluction and autochthonous weathered material, and autochthonous weathered material, respectively. The person in the photograph of site AD4 is sitting on the shoulder of a huge polygon trough, which can be seen in the lower left of the HRSC_AX close-up (photographs of AD1 and AD2 by H. Hiesinger, and AD3 and AD4 by M. Ulrich).

\subsection{Geomorphology and morphometry of Utopia Planitia (UP) polygons}

Polygonal networks in western UP show a zonal distribution that is associated with scalloped terrain. The study of the different polygonal networks allows detailed local analyses in a relatively limited spatial context. Therefore, we focused on one depression, representative of the geomorphological context of scalloped terrain and polygonal structures in UP (Fig. 8). In total, four different types of polygonal networks including 2354 polygons were mapped (Table 3) and classified in and around this depression (UP1 to UP4). Similar to the 

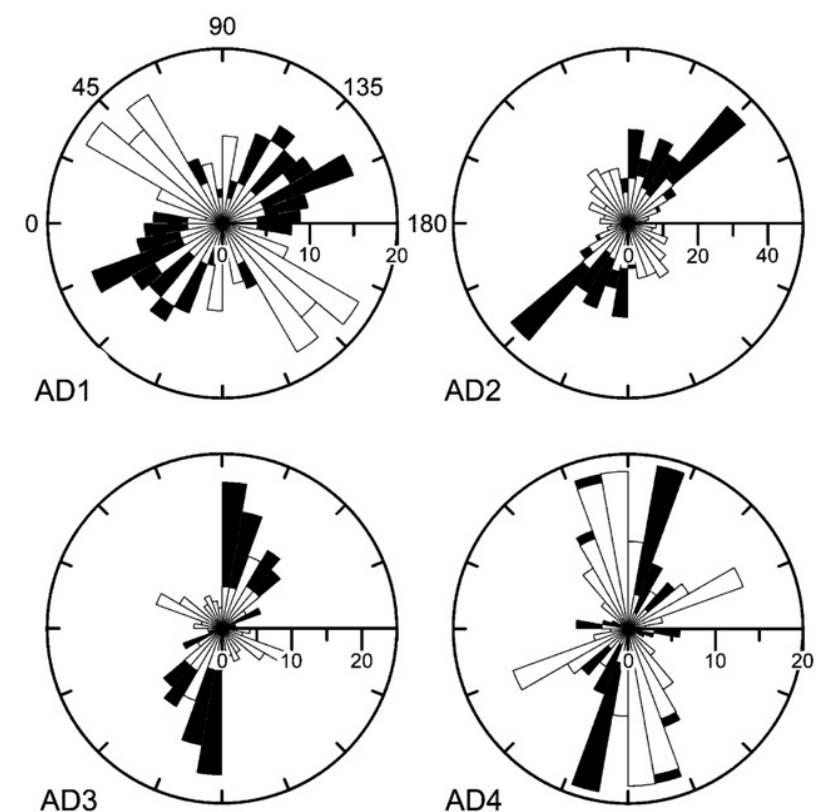

Fig. 6. Orientation of polygon elongation (white) in relation to the direction of slope angle (black) for each terrestrial polygonal field. The ray length represents the number of polygons that fall within a specific angular region. Ray size (binning) is $10^{\circ}$. Note that the $\mathrm{x}$-axes are differently scaled and the rays are vertically mirrored for better visualization.

terrestrial polygons in the Adventdalen, the Martian polygons are uniform with respect to their shape factors (Table 4). Only UP3 polygons reveal a slightly larger variance of the shape factor values and a little larger negative $S K$ in circularity, which statistically would indicate less-elongated polygons (Table 4).

The upper level, representing the non-degraded mantle material in the surroundings of the scalloped depression, is characterized by a random network of large irregular polygons (UP1) (Fig. 8). These polygons range from almost flat to high-centered. The sizes of the mapped UP1 polygons ranges from 13.1 to $88.1 \mathrm{~m}$ (mean $34.3 \mathrm{~m}$ ) (Table 4). Large troughs most commonly 3 to $4 \mathrm{~m}$ wide (max. $>10 \mathrm{~m}$ ) outlines the polygons. Narrow, indistinct cracks in polygon centers form small secondary polygons. The HiRISE DEM indicates trough depths of more than $1 \mathrm{~m}$. The polygonal network at site UP1 shows an orthogonal to hexagonal lattice (Fig. 9). About 93\% of the trough intersections belong to the three-ray type (Table 3). All elongated (i.e. $>15 \%$ longer than wide) UP1 polygons are oriented mainly in the N-S or E-W direction (Fig. 10). The surface around the depression is almost flat. Numerous boulders are distributed randomly in the area (see also Lefort et al., 2009). The polygon troughs seem to be filled with fine-grained dark deposits (Fig. 9). Differences of UP1 polygon shapes and dimensions were observed in relation to the topography around the scalloped depression. The polygons in the southern and southwestern more-elevated area are more distinct and bigger, their outlining troughs are clearly visible, and their centers are rather flat. In contrast, polygons in the north and northeastern lower area are smaller, very bumpy, and appear much more degraded; often only long N-S-trending troughs are visible (Fig. 8). This topographic zonation of the upland polygons could be observed elsewhere in the investigated region.

The small-scale polygons within the scalloped depressions were classified as mixed-center polygons by Levy et al. (2009a). Three different types of polygonal networks were identified (UP2, UP3, and UP4) (Table 3) in connection with the internal morphology of the scalloped depression (Fig. 8). Stripes of low-centered (UP2) and highcentered (UP3) polygons with narrow troughs and cracks alternate concentrically from the north-facing scarp to the depression bottom (Fig. 9). These stripes of polygons are distinctly oriented along the scarp. The polygon troughs and cracks are mainly oriented perpendicular and parallel to the scarp. The relationship can also be seen from the direction of polygon elongation, reflecting the horseshoe shape of the north-facing slope (Fig. 10). The orientation of polygon elongation is much more closely parallel to the slope angle on the steeper parts of the north-facing slope (slope angles $\sim 14^{\circ}$ ). Lowcentered polygons (UP2) show a more distinct orientation than highcentered polygons (UP3). The ridges within the depression are characterized by high-centered polygons with peaked and domed as well as flat elevated centers (UP3) (Fig. 9b). The size of high-centered polygons ranges between 4.3 and $25.6 \mathrm{~m}$ (mean $11.4 \mathrm{~m}$ ) (Table 4). These polygons are orthogonal, but hexagonal geometries exist as well. About $14 \%$ of the counted trough intersections belong to the four-ray type (Table 3). Four concentric zones of high-centered polygons corresponding to four internal ridges were mapped in the depression (Fig. 8). The smallest and most distinct high-centered polygons exist on the less-pronounced ridge close to the scarp edge. Low- to flat-centered polygons with a mean size of $9.8 \mathrm{~m}$ (4.5 to $16.2 \mathrm{~m}$ ) (Table 4) are spread between the ridges (UP2) (Fig. 9). The polygons closest to the scarp edge are characterized by distinct lowlying centers. Pairs of raised rims beside the outlining cracks are visible (Fig. 9a). These strongly-oriented polygons with a clear orthogonal shape exhibit a very homogenous size distribution. The highest percentage of four-ray intersections $(\sim 17 \%)$ among all Martian or terrestrial polygonal fields could be observed within this network (Table 3).

The south-facing slope is also characterized by patterns of low-lying centers (UP4) (Fig. 9c). These patterns overlay a larger polygonal network, indicating residues of upland polygons in this comparatively shallower part of the depression (Fig. 8). The centers of these very small polygons are outlined by raised single ridges (Fig. 9c). Cracks, which typically outline low-centered polygons, were not identified. The polygon sizes at site UP4 range from 3.6 to $13.9 \mathrm{~m}$ (mean $8.1 \mathrm{~m}$ ) (Table 4). The network is characterized by an orthogonal to hexagonal lattice. About $87 \%$ of the mapped intersections at UP4 are of the threeray type (Table 3 ). The orientation of polygon elongation is mainly $\mathrm{N}-\mathrm{S}$ and normal to the average direction of slope angle (Fig. 10). The striking spatial arrangement of the small-scale polygons within the scalloped depression is also visible in other well-pronounced single depressions in the region.

\subsection{Results of the multivariate statistics}

Principal component analyses (PCAs) were conducted and revealed similar results for all polygonal fields. Thus, PCA results are summarized using the example of a combined dataset which includes all investigated sites. The response variables extracted for each polygon (Table 2) are clearly separated on the first two PCA axes. Together, the cumulative percentage of eigenvalues reveals that $79 \%$ of the total variance is explained by PC1 and PC2. Variables representing polygon dimension are clearly correlated to PCA axis 1 , explaining more than half of the variance $(54 \%)$ in the polygon dataset. The PCA axis 2 is related to variables representing polygon shape. About $25 \%$ of the total variance is explained by this axis. The PCA reveals no correlation between dimension variables (PC1) and shape variables ( $\mathrm{PC} 2$ ). The variable CosMA, representing direction of polygon elongation (Table 2), contributes only a little to the explained variance although a negative correlation to the shape factor variables was expected.

In order to identify the specific environmental parameters that predominantly explain polygon shape and dimension, several constrained ordination analyses (RDAs, partial-RDAs) were performed. Variance partitioning (i.e., partial-RDA) with PCNM-analysis-derived spatial variables (see Section 3.4) was used to filter out spatiallystructured effects (i.e., autocorrelation) in the environmental variables. Small but significant portions of the explained variance in most 
Center

$\mathrm{C} / \mathrm{N}$

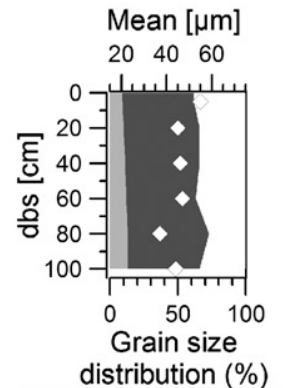

Trough
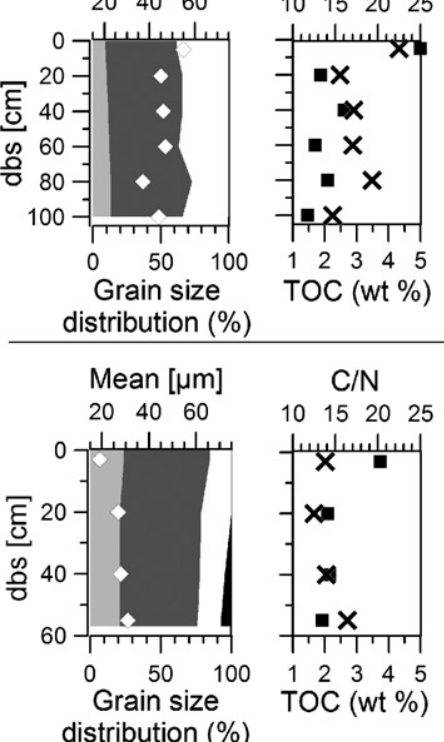

$\mathrm{C} / \mathrm{N} \quad \mathrm{K}\left(\mathrm{W} \mathrm{m}^{-1} \mathrm{~K}^{-1}\right)$

AD1

$\begin{array}{llll}10 & 15 & 20 & 25\end{array}$

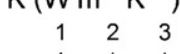

Mean $[\mu \mathrm{m}]$
$20 \quad 40 \quad 60$

$\mathrm{C} / \mathrm{N}$

$\mathrm{K}\left(\mathrm{W} \mathrm{m}^{-1} \mathrm{~K}^{-1}\right)$
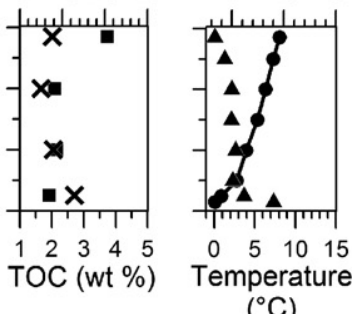

Temperature $\left({ }^{\circ} \mathrm{C}\right)$

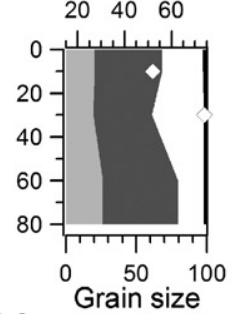

$\begin{array}{llll}10 & 15 & 20 & 25\end{array}$
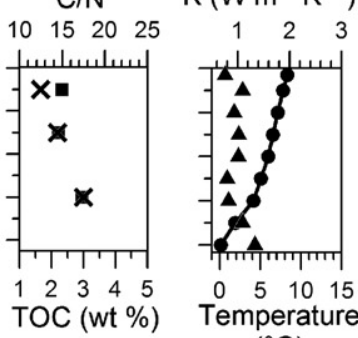

AD2 distribution (\%)

$\left({ }^{\circ} \mathrm{C}\right)$
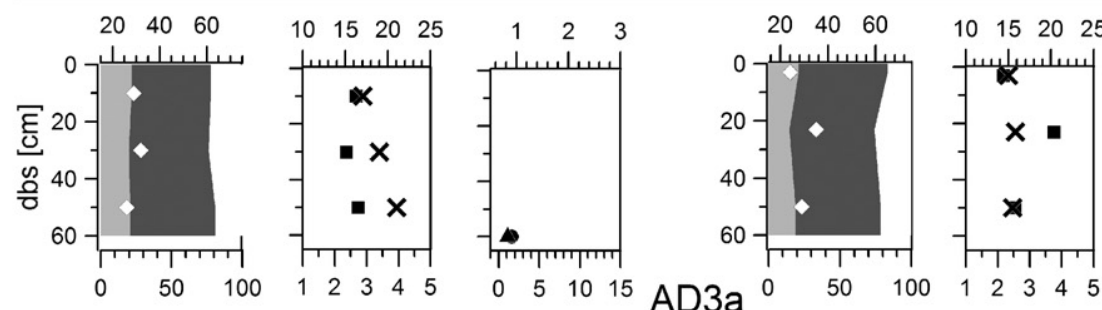

$\begin{array}{lll}1 & 2 & 3\end{array}$

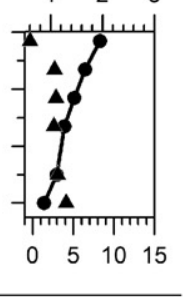

$20 \quad 40 \quad 60$
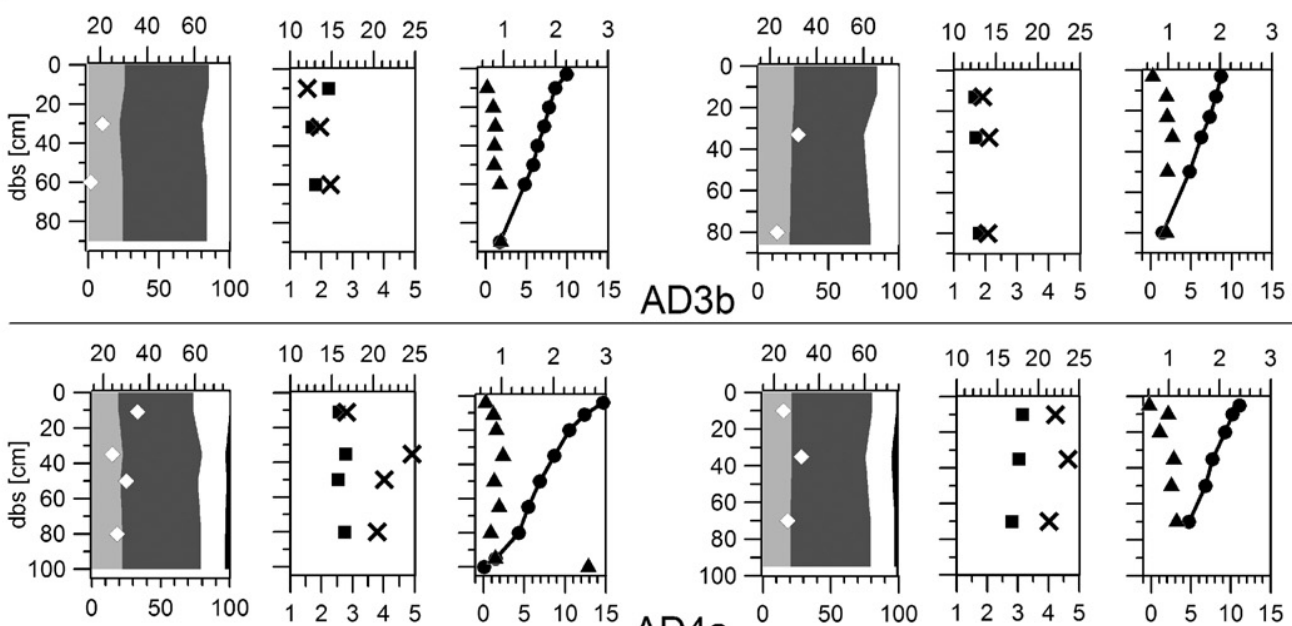

\section{$A D 3 b$}

1234
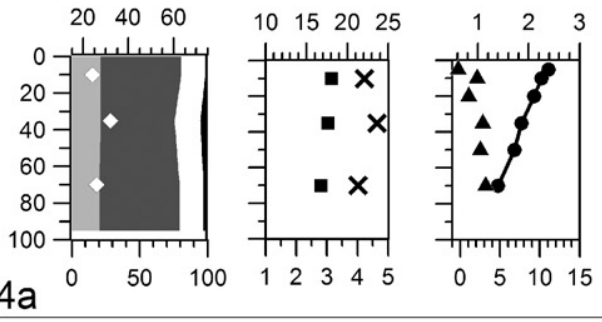
$\diamond$ Mean grain size
- Total organic carbon (TOC)
$\times \mathrm{C} / \mathrm{N}$ ratio
- Ground temperature
- Thermal conductivity $(\mathrm{K})$

Clay $(<2 \mu \mathrm{m})$ Sand (63 to $2000 \mu \mathrm{m}$ ) Silt (2 to $63 \mu \mathrm{m})$ Gravel (>2000 $\mu \mathrm{m})$
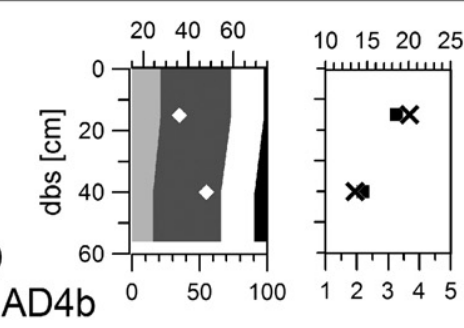

Fig. 7. Active-layer sediment data and thermal properties from centers and troughs of selected polygons at each Adventdalen polygonal field (for locations see Fig. 4). Parameters are plotted against depth below surface (dbs). Note the different scales of the $y$-axes. The bottom end of the grain-size distribution signatures represent the active-layer depths, except for AD1 in which an active-layer depth of around $60 \mathrm{~cm}$ was observed. The thermal conductivity and ground temperature data have been averaged over 3-4 measurements at different depths.

of the polygon dataset are primarily related to the elevation effect (i.e., $R H$ ), and secondarily to aspect (i.e., $E a$ ) and slope angle. Fig. 11 presents the results of variance partitioning. The bar plots illustrate the unexplained amount of variance in the dataset, as well as the amount explained by non-spatially-structured (i.e., pure) environmental factors, by the spatial variables alone, and by the spatially- 


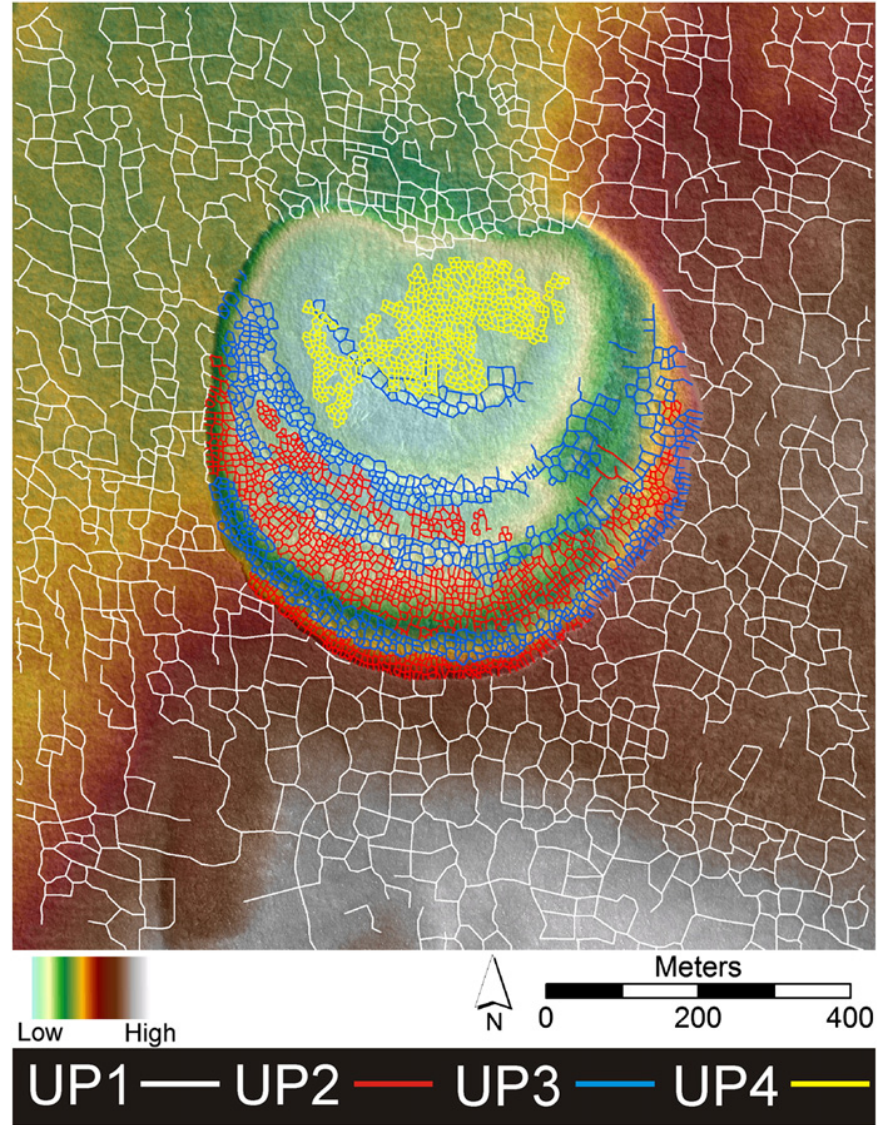

Fig. 8. Mapped polygonal field in western Utopia Planitia. The polygons that make up the polygonal fields UP2, UP3, and UP4 are indicated by colors in the scalloped depression. Topography is illustrated by a HiRISE DEM subset $\left(1 \mathrm{~m} \mathrm{pixel}^{-1}\right.$, stereo pair: PSP_001938_2265_PSP002439_2265).

structured components shared by the environmental and spatial variables. Large amounts of the explained variance are related to spatial factors, because neighboring polygons are often quite similar and polygon formation depends on the spatial position. RDA triplots are only exemplarily shown for sites AD3 and UP1 (Fig. 12). All significant environmental and spatial variables (named PCNM) are plotted in relation to the response variables. Environmental and spatial variables which lost their significance after forward selection are marked. For site AD3, 7.4\% of the explained variance is attributed to the pure elevation effect (Fig. 11). Ea was excluded after forward selection. $R H$ shows clear correlation with the shape $F F, A R$, and $T h$ (Fig. 12a), but only a small correlation to the dimension variables. For site UP1, $6.3 \%$ of the explained variance is attributed to the pure effect of $R H$ and Slo. No was excluded after forward selection (Fig. 11). In the corresponding RDA triplot (Fig. 12b), polygon dimension variables are positively correlated with $R H$ but negatively correlated with the slope angle. Generally, a similar positive correlation of $R H$ to the dimension variables is calculated in all site-specific RDAs in which $R H$ was significant after forward selection (Fig. 11). A negative correlation is obvious only for sites AD4 and UP3. Furthermore, in site UP3, aspect represented by $E a$ has more explanatory power as $R H$. Slo and No were excluded here after forward selection. For site AD2, only Slo was significant after forward selection and Ea was excluded. Even if only very little variance can be explained by the pure effect of Slo after variance partitioning for this site (Fig. 11), slope angle shows a distinct correlation to the shape factors in the associated RDA triplot. After forward selection for site UP2, all environmental variables, which were significant before, must be excluded. Therefore, the explained variance at this site can only be attributed to the spatial variables. The highest amounts of variance $(>80 \%)$ unexplained by either the environmental or the spatial variables were found for sites AD2 and UP4.

\section{Discussion}

5.1. Relationship between geomorphometry and genesis for the terrestrial polygons

The four polygonal fields in the Adventdalen are homogeneous with respect to their geomorphometric parameters. The statistical characteristics of $F F, A R$, and $T h$ are similar for all sites (Table 4). However, the differing surface morphologies and dimensions indicate different stages of evolution (Table 5). The smallest and youngest polygons exist in the lower Adventdalen on flat terraces near the Adventelva River (site AD1). These are recently-active low-centered ice-wedge polygons. Active thermal contraction cracking is proven, and relatively large ice wedges exist below the wider furrows at site AD1 (Matsuoka and Hirakawa, 1993; Christiansen, 2005). The ongoing activity of thermal contraction cracking has resulted in progressive polygon subdivision (Table 5), expressed by a higher frequency of four-ray intersections compared to site AD2, AD3, and AD4 (Table 3). Therefore, these polygons are regular in shape and smaller in size (Lachenbruch, 1966). The largest high-centered polygons were observed in the central valley at site AD2. The dimensions of the observed high-centered polygons decrease from the central valley to the upper Adventdalen, but ages are probably increasing. The dating of pingo and ice-wedge material suggests that periglacial landform formation in the lower Adventdalen was initiated about 3000 yr BP (Svensson, 1971; Jeppesen, 2001). The late Holocene age of polygons in the lower Adventdalen (e.g., AD1) is likely, as they are located below the uppermost Holocene marine limit $(\sim 70 \mathrm{~m}$ above the present sea level). The relative sea level had fallen to the present-day position not until about $4300 \mathrm{yr}$ BP (Lønne and Nemec, 2004). Certainly, pingo ages have been identified to increase up the valley to about 7000 yr BP (Yoshikawa and Nakamura, 1996; Ross et al., 2007; Meier and Thannheiser, 2009 and references therein). In general, this points to an older periglacial landform formation in the upper Adventdalen. Smaller high-centered polygons in the upper Adventdalen (AD4) have probably resulted from comparatively more permanent activity in the Holocene and thus enhanced polygon subdivision. The widths of the outlining troughs definitely increase in the up-valley direction to site AD4. This observation is in agreement with Malmström et al. (1973) who found the oldest and bestdeveloped troughs on the highest terraces in this region. Furthermore, the same authors suggest a direct correlation between the width of ice wedges and the width of the overlying troughs. Based on the observed lack of ice wedges just below the active layer and of frost cracks extending through the active layer, which are regarded as indicators of wedge activity (e.g., Romanovskii, 1985; Mackay, 1992), the highcentered polygons in the central and upper Adventdalen are classified as inactive. The degradation and thawing of ice wedges have resulted in wide and deep troughs. This is supported by the relationship between larger trough widths and steeper slope angle. The evolutionary change from low-centered to high-centered polygons caused by ice-wedge degradation (e.g., Washburn, 1979; Mackay, 2000) might be reinforced on slopes by increasing drainage along the polygon-outlining troughs (Fortier et al., 2007). This degradation factor dominates the recent development of the high-centered polygons in the middle and upper Adventdalen and prevents active frost cracking (Table 5); this is also true because snow accumulating in the deep troughs would have an insulating effect, preventing crack initiation (e.g., Mackay, 1974, 1992). Crack formation is influenced by micro-climate, micro-relief, vegetation, and snow cover, and therefore by specific temperature conditions (Christiansen, 2005; Fortier and Allard, 2005), which further complicates the discussion of differing 

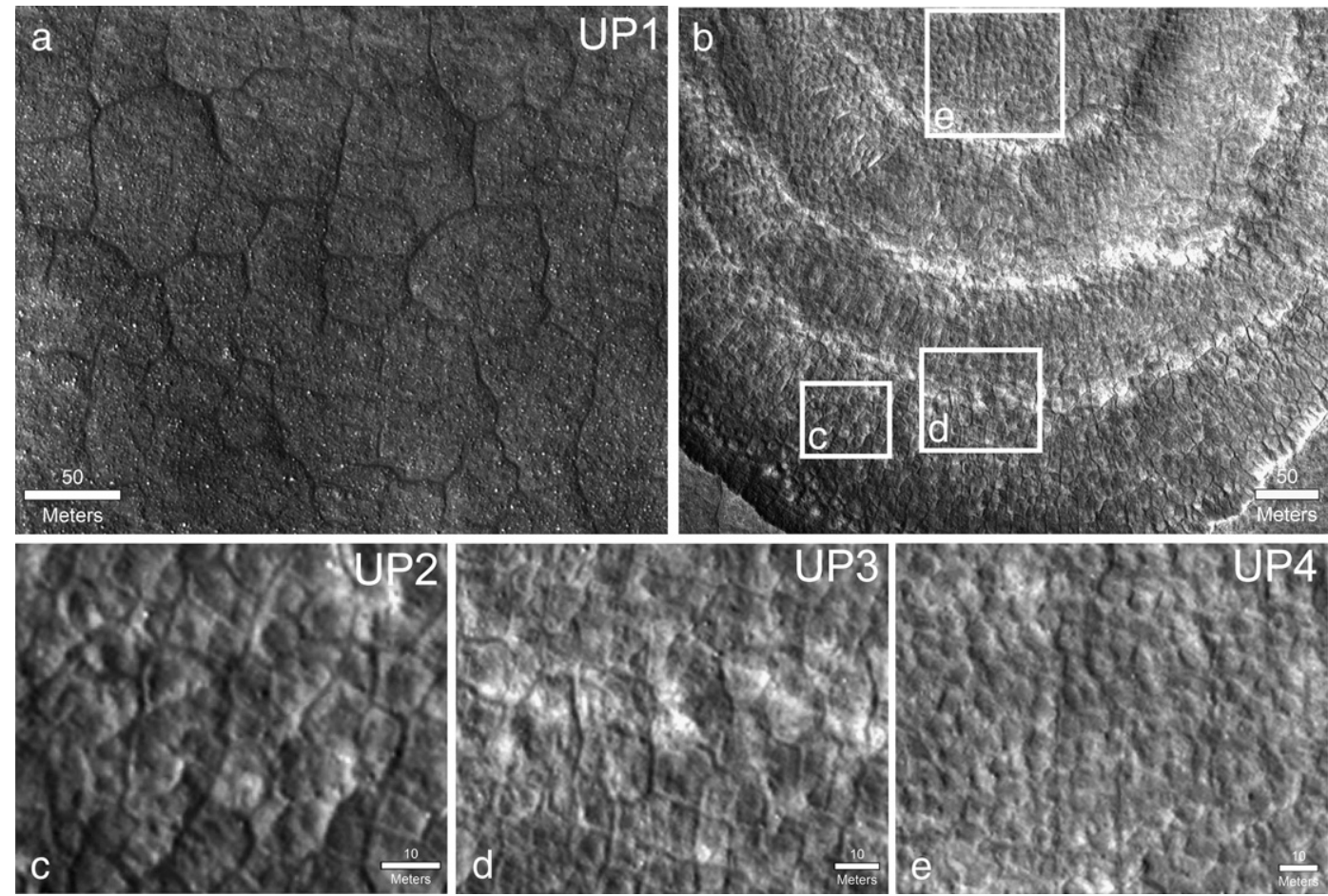

Fig. 9. Close-up of each polygonal field in Utopia Planitia. (a) Large flat- to high-centered polygons on the uplands in the south of the scalloped depression. (b) Context of the polygonal network connected to the internal morphology of the scalloped depression. (c) Low-centered polygons with raised ridges flanking outlining fissures. (d) High-centered polygons on one of the interior scallop ridges. Smaller examples can be seen close to the north-facing scarp on the upper left image. (e) Low-centered polygons with single raised ridges overlying a larger polygonal network on the south-facing slope of the scalloped depressions. Cracks that outline the polygons are not visible. (Each subset from HiRISE image: PSP_001938_2265).

cracking activity in the Adventdalen. The change in cracking activity is thought to reflect a change in climate (French, 2007). Conditions more favorable to frost cracking than those of today (e.g., lower ground temperatures) probably existed in the middle and upper Adventdalen earlier in the Holocene.

The sedimentological properties of all active-layer profiles are relatively uniform, reflecting less variability in surficial material than
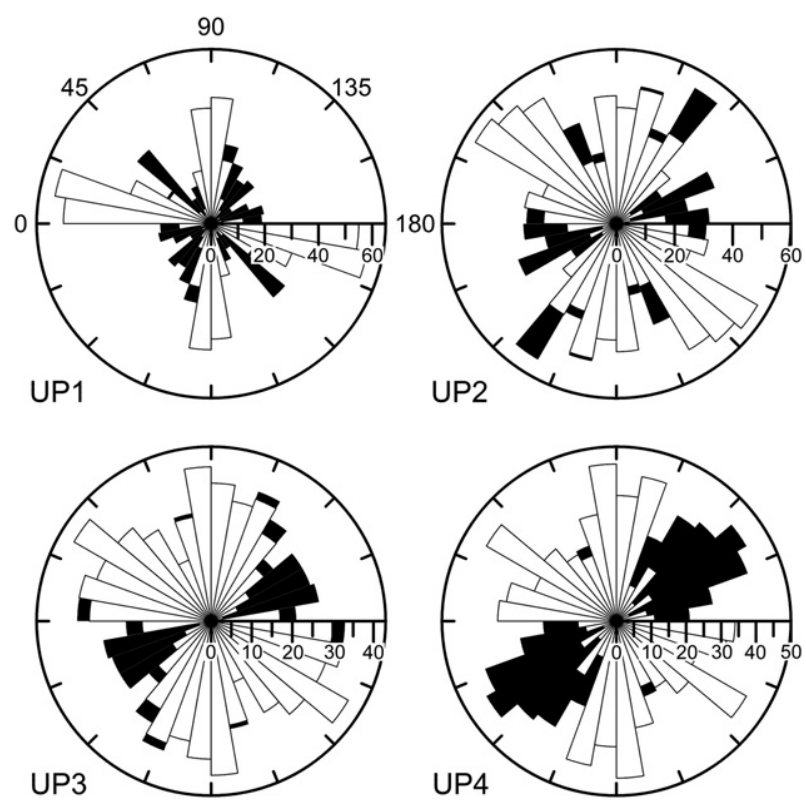

Fig. 10. Orientation of polygon elongation (white) in relation to the direction of slope angle (black) for each Martian polygonal field. The ray length represents the number of polygons that fall within a specific angular region. Ray size (binning) is $10^{\circ}$. Note that the $\mathrm{x}$-axes are differently scaled and the rays are vertically mirrored for better visualization. suggested by Tolgensbakk et al. (2001). Only small differences due to varying gravel contents were observed between the sites. Higher contents of gravel, in particular at the high-centered polygon sites in the upper Adventdalen, would be in agreement with current inactive thermal contraction cracking, because coarser-grained sediments require lower ground temperatures for cracking $\left(<-6{ }^{\circ} \mathrm{C}\right.$; Romanovskii, 1985) than the existing average permafrost temperatures on Svalbard $\left(-2.3^{\circ} \mathrm{C}\right.$ to $-5.6{ }^{\circ} \mathrm{C}$; Christiansen et al., 2010). Furthermore, we found that the smallest polygons are associated with the homogenous silty loess-like deposits in the lower Adventdalen (AD1). The largest polygons are associated with higher gravel contents in the middle valley (AD2), i.e., with more compositionally heterogeneous sediments. This agrees with the suggestion of Lachenbruch $(1962,1966)$, that smaller regular polygons are related to homogenous fine-grained sediments with higher ground-ice contents due to the larger expansion coefficient and higher thermal stress. In contrast, larger irregular polygons are related to heterogeneous coarser-grained sediments (Table 1 ). Thus, we assume relatively high ground-ice contents at site AD1. At site AD4, the polygon size changes in accordance with the hillslope gradient and a change in grain-size distribution. Larger polygons, located downslope, are associated with the highest measured contents of gravel (AD4b in Fig. 7). By comparison, on the more elevated and horizontal parts, smaller polygons have formed in material with lower gravel contents and smaller mean grain size (AD4a, see also Fig. 5). Furthermore, the polygonal network is rather irregular and shows a non-orthogonal lattice at its elevated parts. Down the slope, the larger polygons are mainly orthogonal (Fig. 4). The relationship of ground material homogeneity to the orthogonality of polygonal systems is a further topic of debate (Table 1). Most authors suggest that non-orthogonal (i.e., hexagonal) and complex systems are formed in homogenous material, while orthogonal lattices are related to heterogeneous material (Lachenbruch, 1962; French, 2007). Such relationships could not be confirmed by our observations in the Adventdalen. With regard to the intra-site differences at $\mathrm{AD} 4$, orthogonal polygons are 


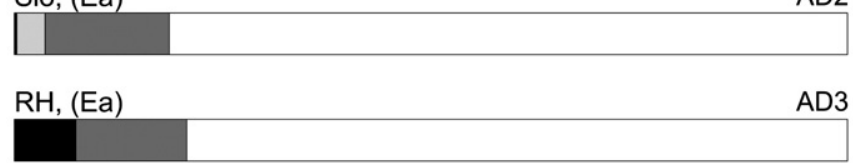

$\mathrm{RH}$, Slo, (Ea)

AD4

$\mathrm{RH}, \mathrm{Slo},(\mathrm{No})$

UP1

$(\mathrm{RH}),(\mathrm{Slo}),(\mathrm{Ea}),(\mathrm{No}) \quad$ UP2

$(\mathrm{RH}),(\mathrm{Slo}),(\mathrm{Ea}),(\mathrm{No})$

$\mathrm{RH}, \mathrm{Ea}$

UP4

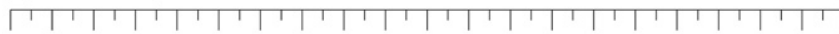

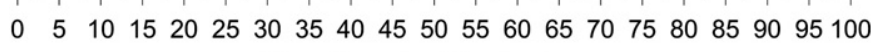
Percentage of explained variance

Explained by environmental variables Shared effect

Explained by spatial variables Unexplained variance

Fig. 11. Results of variance partitioning for each investigated terrestrial (AD1-AD4) and Martian (UP1-UP4) polygonal field. For each site the bar plot shows the different explained proportions of variance. The environmental variables explaining significant amounts of variance are listed on the left above the plots. Variables which were finally excluded after forward selection are given in parentheses. Variable abbreviations are used according to Table 2. For further explanations see text.

associated with more heterogeneous ground material down the slope. The regular AD1 polygonal network with partly orthogonal structures (Figs. 4 and 5 and Table 5) formed in homogenous ground material (see above).

The direction of polygon elongation was measured to estimate the direction of primary cracking. The majority of polygons within all polygonal fields are elongated (i.e., they are 15\% longer than width); only a few polygons are characterized by their similar width and length. Theoretically, if first-order cracks are long and subsequently subdivided by shorter secondary cracks as has been modeled by Plug and Werner (2001), the primary cracks would determine the direction of polygon elongation in most cases. A distinct orientation of polygon elongation with respect to the direction of slope angle could be determined for the Adventdalen polygons (Fig. 6). However, all polygonal networks are randomly formed in sensu Lachenbruch $(1962,1966)$ and are therefore not oriented to stress-free vertical zones such as the shore of the Adventelva River. Nevertheless, at the sites where the polygonal fields are formed on steeper slopes, in particular at sites AD3 and AD4 (Fig. 4), the primary cracking seems to have occurred normal to the contour as polygon elongation is mainly parallel to the slope angle (Fig. 6). Mackay and Burn (2002) reported similar primary crack orientation on the slopes of a drained lake site in the western Canadian Arctic. At our AD1 Adventdalen site, where the polygonal field is formed on a very gentle slope and in a rather flat area, polygon elongation is mainly parallel to the contour. A similar relationship was visually observed for the gentle slope sections at site AD2. These observations led to the assumptions that the gravitational effects on steeper slopes affect the direction of primary thermal contraction cracking and, furthermore, the orientation of polygons, because the secondary cracking occurs along the contour (Mackay and Burn, 2002).
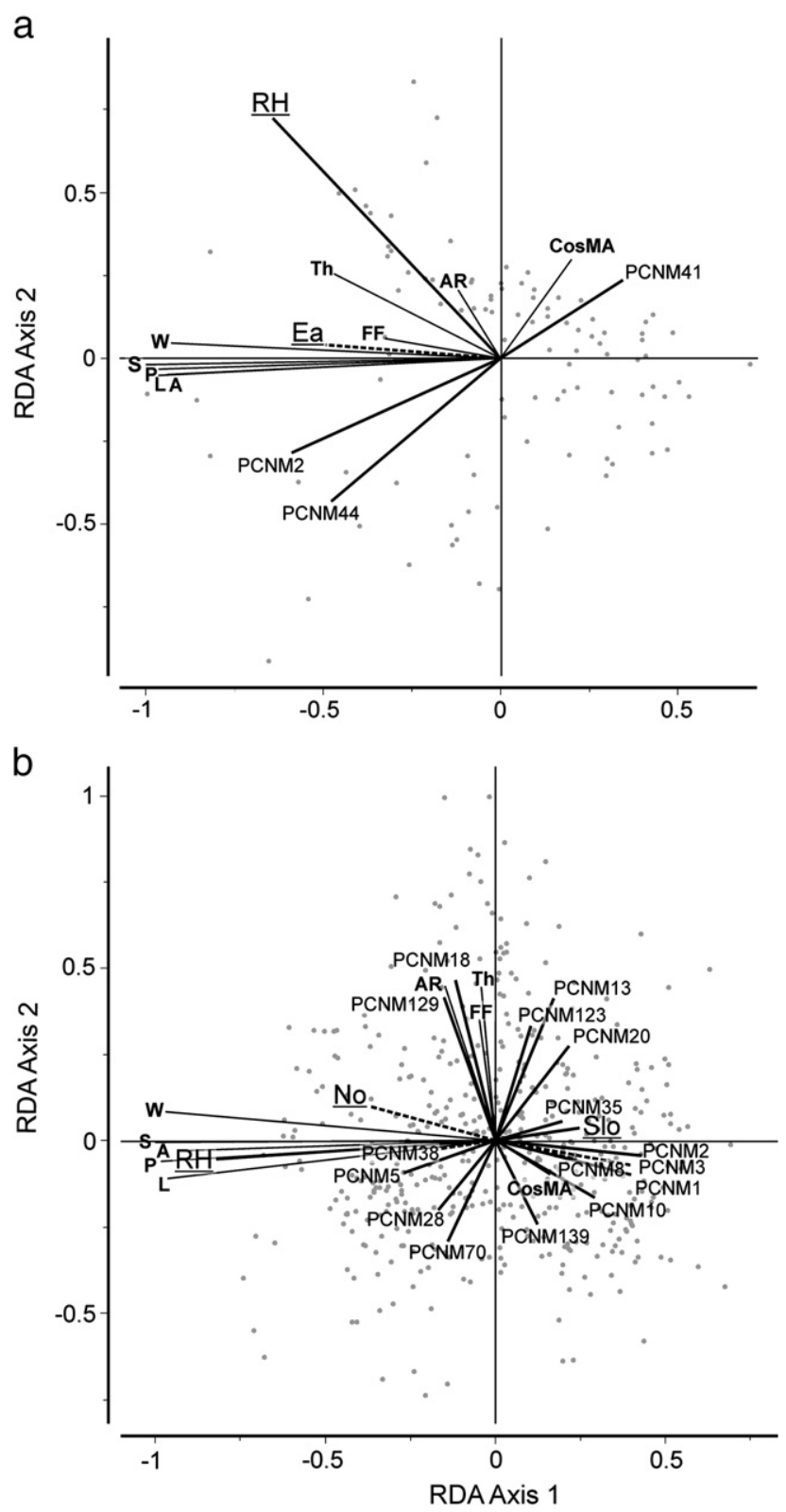

Fig. 12. Example of redundancy analysis (RDA) triplots for (a) site AD3 and (b) site UP1 showing the relationship of significant environmental (thick solid lines, underlined letters) and significant spatial (PCNM, thick solid lines, simple letters) variables to the response variables (thin solid lines, bolded letters). Environmental variables which were excluded after forward selection are illustrated as dotted lines. The gray dots illustrate the locations of polygon samples. Abbreviations are used according to Table 2.

The statistical analysis reveals differences within the individual polygonal fields in accordance with the site-specific conditions. Thus, the polygon geomorphometry is related to topographical conditions. The results of our multivariate statistics show that polygon dimension and shape are related to the location within a polygonal field, as expressed by the highly significant influence of $R H$ on almost all polygonal fields (Fig. 11). This variable probably represents unmeasured or statistically unconsidered factors that vary along a hillslope gradient within the polygonal field, such as ground-ice and moisture contents, thermal conductivity (e.g., influenced by snow and vegetation cover), or grain-size distributions. Aspect and slopeangle conditions play a minor role in the statistics of our polygon dataset. This is unexpected, as subsurface and micro-climate conditions also change with slope angle and aspect and should have an influence on initial thermal contraction cracking and subsequent 
Table 5

Compilation of morphometric criteria as well as past and present formation processes in the studied terrestrial and Martian polygonal fields. Question marks refer to processes which are not entirely clarified. For instance, composite-wedge formation at the Martian sites UP2 and UP3 would have occurred only during high-obliquity conditions in the past.

\begin{tabular}{|c|c|c|c|c|c|c|c|c|}
\hline & \multicolumn{4}{|l|}{ Earth } & \multicolumn{4}{|l|}{ Mars } \\
\hline & AD1 & AD2 & AD3 & AD4 & UP1 & UP2 & UP3 & UP4 \\
\hline Shape & Similar & Similar & Similar & Similar & Similar & Similar & Similar & Similar \\
\hline Average size & $<20 \mathrm{~m}$ & $<30 \mathrm{~m}$ & $<30 \mathrm{~m}$ & $<30 \mathrm{~m}$ & $>30 \mathrm{~m}$ & $<10 \mathrm{~m}$ & $<20 \mathrm{~m}$ & $<10 \mathrm{~m}$ \\
\hline Polygon center & Low & High & High & High & High & Low & High & Low \\
\hline $\begin{array}{l}\text { Orientation to } \\
\text { stress-free } \\
\text { vertical } \\
\text { surfaces }\end{array}$ & No & No & No & No & No & $\begin{array}{l}\text { Strong near the topographic } \\
\text { scarp }\end{array}$ & $\begin{array}{l}\text { Strong near the } \\
\text { topographic scarp }\end{array}$ & No \\
\hline $\begin{array}{l}\text { Network } \\
\text { orthogonality }\end{array}$ & Partial & More complex & More complex & $\begin{array}{l}\text { Partial on } \\
\text { steeper slope } \\
\text { sections }\end{array}$ & Partial & $\begin{array}{l}\text { Distinct near the } \\
\text { topographic scarp }\end{array}$ & $\begin{array}{l}\text { Distinct near the } \\
\text { topographic scarp }\end{array}$ & More complex \\
\hline $\begin{array}{l}\text { Origin of mean } \\
\text { polygon } \\
\text { elongation }\end{array}$ & Random & Random & Gravitational & Gravitational & Gravitational? & $\begin{array}{l}\text { Gravitational and stress } \\
\text { release at vertical surface }\end{array}$ & $\begin{array}{l}\text { Gravitational and } \\
\text { stress release at } \\
\text { vertical surface }\end{array}$ & Random \\
\hline $\begin{array}{l}\text { Polygon } \\
\text { subdivision }\end{array}$ & $\begin{array}{l}\text { Medium, } \\
\text { increasing }\end{array}$ & Low, stopped & Low, stopped & $\begin{array}{l}\text { Medium, } \\
\text { stopped }\end{array}$ & Low, stopped & High, increasing? & High, stopped & Medium, stopped \\
\hline $\begin{array}{l}\text { Wedge } \\
\text { formation }\end{array}$ & Ice-wedge & Ice-wedge & Ice-wedge & Ice-wedge & Sand-wedge? & $\begin{array}{l}\text { Sand-wedge, Composite- } \\
\text { wedge? }\end{array}$ & $\begin{array}{l}\text { Sand-wedge, } \\
\text { Composite- } \\
\text { wedge? }\end{array}$ & Sand-wedge? \\
\hline $\begin{array}{l}\text { Current } \\
\text { dominant } \\
\text { process }\end{array}$ & $\begin{array}{l}\text { Active } \\
\text { cracking, } \\
\text { Ice-wedge } \\
\text { growth }\end{array}$ & $\begin{array}{l}\text { Degradation } \\
\text { by thawing of } \\
\text { ice-wedges }\end{array}$ & $\begin{array}{l}\text { Degradation } \\
\text { by thawing of } \\
\text { ice-wedges }\end{array}$ & $\begin{array}{l}\text { Degradation } \\
\text { by thawing of } \\
\text { ice-wedges }\end{array}$ & $\begin{array}{l}\text { Sublimation of } \\
\text { ground-ice within } \\
\text { polygon troughs }\end{array}$ & $\begin{array}{l}\text { Active cracking (limited to } \\
\text { favorable local conditions), } \\
\text { Sand-wedge growth? }\end{array}$ & $\begin{array}{l}\text { Sublimation of } \\
\text { ground-ice within } \\
\text { polygon troughs }\end{array}$ & $\begin{array}{l}\text { Sublimation of } \\
\text { ground-ice within } \\
\text { polygon centers }\end{array}$ \\
\hline Origin & $\begin{array}{l}\text { Thermal } \\
\text { contraction } \\
\text { cracking }\end{array}$ & $\begin{array}{l}\text { Thermal } \\
\text { contraction } \\
\text { cracking }\end{array}$ & $\begin{array}{l}\text { Thermal } \\
\text { contraction } \\
\text { cracking }\end{array}$ & $\begin{array}{l}\text { Thermal } \\
\text { contraction } \\
\text { cracking }\end{array}$ & $\begin{array}{l}\text { Thermal } \\
\text { contraction } \\
\text { cracking }\end{array}$ & $\begin{array}{l}\text { Thermal contraction } \\
\text { cracking }\end{array}$ & $\begin{array}{l}\text { Thermal } \\
\text { contraction } \\
\text { cracking }\end{array}$ & $\begin{array}{l}\text { Thermal } \\
\text { contraction } \\
\text { cracking? }\end{array}$ \\
\hline
\end{tabular}

polygon formation (e.g., Lachenbruch, 1966; Mackay, 2000; Mackay and Burn, 2002). Furthermore, interrelationships of slope conditions and polygon shape or dimension could be observed, as was discussed above. However, this was only slightly apparent in the statistics for the AD2 and AD4 Adventdalen sites (Fig. 11).

\subsection{Comparability of terrestrial and Martian polygonal structures}

The investigated polygonal structures in western UP on Mars share the geomorphological and morphometrical characteristics of the Adventdalen polygons. By comparing diverse geomorphometric criteria, several points are discussed by analogy (Table 5). The polygonal structures of western UP belong to the category of smallscale patterns, according to classifications of the wide variety of polygonal structures on Mars (e.g., Mangold, 2005; Levy et al., 2009a). Besides the analogy to the terrestrial polygons, the thermal contraction cracking origin is more likely than other origins such as desiccation cracking, as the landscape assemblage in the region points to a dry origin and there is no evidence of former lakes (Ulrich et al., 2010) or water-rich sediments essential for desiccation (El Maarry et al., 2010). The statistical properties indicate that the shape of the observed Martian and terrestrial polygons are similar (Table 4). Additionally, the sizes of the UP polygons are comparable to those of the Adventdalen polygons and fall within the range of maximum fracture spacing under current climate conditions on Mars $(<75 \mathrm{~m}$, El Maarry et al., 2010). They are also significantly smaller than polygons of tectonic origin (e.g., Hiesinger and Head, 2000). Thus, we can conclude that they originated by thermal contraction cracking in connection with near-surface ground ice (Mellon, 1997; Mangold et al., 2004) (Table 5). The morphological differences between the observed Martian polygons reflect different ages, thermal contraction cracking activity, and local environmental conditions, similar to their terrestrial analogs. In both cases, flat- to high-centered polygons are separated by distinct outlining troughs. The trough widths and depths of the large high-centered polygons (UP1) as well as their older appearance suggest that the Martian upland polygons have undergone continuous degradation (Lefort et al., 2009). In contrast to the
Adventdalen high-centered polygons, where the trough expansion is related to ice-wedge degradation, it is suggested that the enlargement of polygon troughs on present-day Mars occurred by progressive sublimation of interstitial ice exposed after initial thermal contraction cracking (Mangold, 2005; Levy et al., 2010). Examples of such highcentered sublimation polygons are known from Beacon Valley, Antarctica (Marchant et al., 2002). These high-centered polygons are formed on sediments which cover massive ice bodies (e.g., a stagnant glacier) by thermal contraction and the absence of a liquid phase. Polygon troughs are formed as sublimation is enhanced within the cracks due to the higher porosity and permeability of material trapped therein (Marchant and Head, 2007). From the abundance of high-centered polygons on Mars, Levy et al. (2009a) estimated that sublimation of ground ice in the absence of liquid water is the dominant formation process of Martian polygon morphology. This is consistent with the current very cold and dry climate on Mars. The geomorphology of the polygonal network observed at site UP1 is more likely to have resulted from interstitial ice sublimation than from icewedge degradation in the current stage of climate.

Our data indicate a comparable frequency of three-ray intersections in the terrestrial and Martian high-centered polygons (Table 3), which is a sign of a lower degree of polygon subdivision (Table 5) by ongoing cracking and, therefore, older ages. This interpretation is supported by the larger polygon dimensions, which suggest older features formed under past environmental conditions (e.g., Mangold et al., 2004; see also next section). No clear relationship was observed between a higher frequency of three-ray intersections and mainly hexagonal polygon geometry. Within the terrestrial and Martian polygonal fields, which exhibit more than $90 \%$ three-ray intersections, orthogonal polygons are ubiquitous as well. The high frequency of three-ray intersections further points to a random formation of the polygonal networks (e.g., AD2 and UP1), as four-ray intersections are more typical of orthogonal polygons oriented at topographical edges (e.g., Lachenbruch, 1966; Romanovskii, 1977), like in the UP2 and UP3 Martian polygonal networks (Fig. 9c,d).

A striking feature of the UP1 polygons is the distinct twodirectional polygon elongation (i.e., N-S and E-W) which shows 
only a small relationship to the slope angle direction (Fig. 10). Yoshikawa (2003) reported a similar observation in UP for slightly larger polygons and interpreted the predominantly $\mathrm{N}-\mathrm{S}$ crack orientation as a sign of tectonic origin. Because the region is gently rising to the south, the observed orientation of polygon elongation would be in agreement with the notion (for terrestrial polygons) that the gravitational effect of the slope influences thermal contraction cracking, controlling crack initiation even if the slope angle is very low (French, 2007). The two-directional polygon elongation could therefore be explained by even a very low slope angle (Table 5). The primary cracking occurred in equal parts along and perpendicular to the contour. Other possible explanations exist, such as energy transfer by warmer winds coming from a southern direction during summer (Morgenstern et al., 2007). Winds could possibly increase temperature gradients and thus crack propagation in N-S-trending troughs, resulting in perpendicular secondary cracks forming in the EW direction.

Like the terrestrial low-centered polygons (AD1), the small Martian polygons (UP2) are characterized by pairs of raised rims beside the outlining fissures. The low-centered polygons on the south-facing scalloped depression slope (UP4) are exceptional, since they are characterized by single outlining ridges without fissures between them (Fig. 9e). The UP2 polygons, particularly those situated close to the steep north-facing wall of the scalloped depression (Fig. 9c), show close similarities to the active low-centered polygons (AD1) in Adventdalen. In direct analogy, their fresh appearance as compared to the upland UP1 polygons, their small size, and their clear orthogonal lattice point to recently-active thermal contraction cracking processes due to homogenous fine-grained ice-rich material (Lachenbruch, 1962, 1966; Lefort et al., 2009). Besides the distinct orthogonality of the UP2 polygons, the orientation of polygon elongation (Fig. 10 and Table 5), which is clearly parallel to the slope angle, suggests the primary cracking occurs perpendicular to the contour as the result of stress release at the scarp edge, and is further induced by the gravitational stress of the slope (Fig. 13). Similar observations are reported by Levy et al. (2009a) for polygons present in Martian gully alcoves and by Mangold (2005) who also relates the orientation of orthogonal polygons inside Martian crater walls to the effect of slope. The orientation changes to a random orthogonal system at the foot of crater flanks. This is in agreement, first, with the observed changes in the character of the Martian UP2 and UP3 polygons to a random and increasingly complex network towards the depression bottom (Fig. 13). Second, a similar change in polygon geometry was described for site AD4 in the Adventdalen where orthogonal structures are mainly grouped on steeper slope sections.

The above suggestion for the highly significant influence of $R H$ within the multivariate statistics (Section 5.1) also applies to the Martian polygonal fields. This is particularly obvious for the UP1 polygonal field (Figs. 11 and 12) as the statistics confirm the visual observation explained in Section 4.3, i.e., that polygons in the lower area north of the depression are a little smaller, very bumpy and appear more degraded compared to the UP1 polygons south of the depression. Slightly varying ground-ice conditions or even small-scale changes in albedo would have led to different polygon morphologies. Another interesting detail is the statistically higher influence of aspect (represented by the variable $\mathrm{Ea}$ ) as compared to $\mathrm{RH}$ on the polygonal characteristics at site UP3 (Fig. 11). The polygon geomorphometry changes with increasing degradation of the UP3 polygons towards the depression bottom because sublimation would be significantly lower on a north-facing slope than on a south-facing slope due to reduced insolation (Fig. 9b). These interpretations of the multivariate statistical results highlight the helpfulness of this approach in interpreting initial polygon geomorphometry as a function of sitespecific conditions. Moreover, these discussions demonstrate the relationship of secondary polygon morphology to individual topographic conditions.
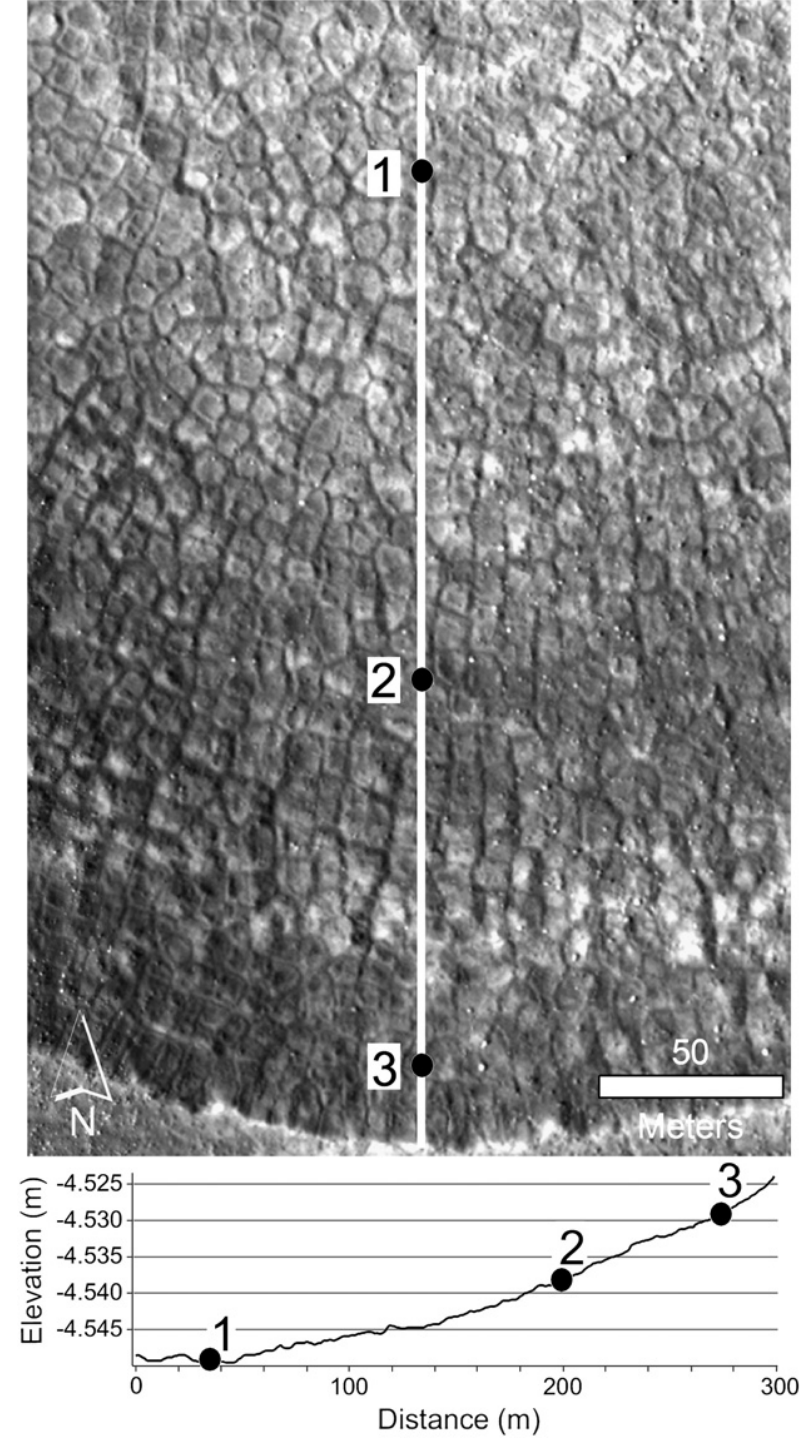

Fig. 13. HiRISE subset showing small polygons of UP2 and UP3 character on the northfacing slope of a large scalloped depression adjacent to the main study site. This example is representative of how polygon morphology changes in response to the slope angle and the distance to the scarp edge. Polygons are clearly orthogonal and cracks are strongly oriented at point 3 . Polygons become increasingly randomly distributed, their orthogonality decreases, and troughs (i.e., cracks) widen towards the depression bottom (point 1). The location of the DEM-derived topographic profile (below) is marked by the white line in the image. (HiRISE image: PSP_001938_2265).

\subsection{Genesis of Mars polygons and environmental implications}

Based on our terrestrial studies and considering the landscape assemblage in UP, some implications for the formation of the Martian polygonal structures can be drawn (Fig. 14). The large upland polygons (UP1) are probably very old and were formed after the deposition of the mantling material during conditions of high obliquity (Kreslavsky and Head, 2000, 2002; Mustard et al., 2001; Head et al., 2003). An old age is also indicated by the fact that these polygons are truncated by the scalloped depressions (Fig. 2c). Troughs are often traceable across the steep north-facing scarps (Lefort et al., 2009; Ulrich et al., 2010) and the original polygonal network is visible in shallow depressions nearby or on south-facing slopes (see Section 4.3), where the lowering of the surface has not yet reached the maximum depths of the cracks (Lefort et al., 2009). The sizes of the polygons indicate very deep thermal contraction cracking, which must be related to strong temperature gradients (Lachenbruch, 1962, 


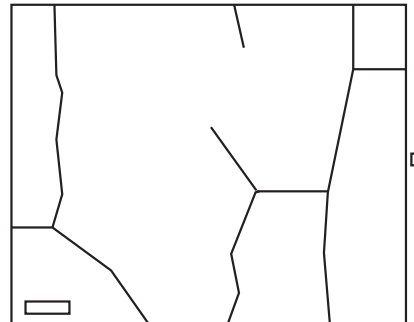

Initial stage UP1

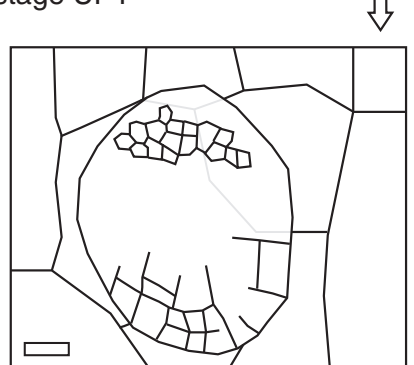

Initial stage UP2, UP3, UP4

Deposition of

mantling material (higher obliquity)

$\sqrt{3}$

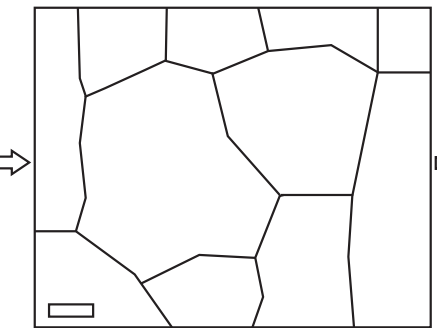

$\Rightarrow$

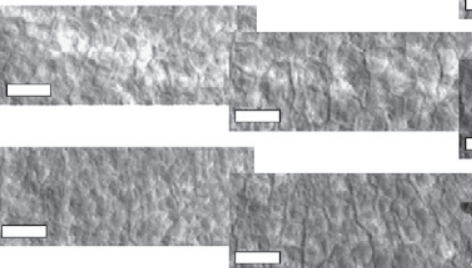

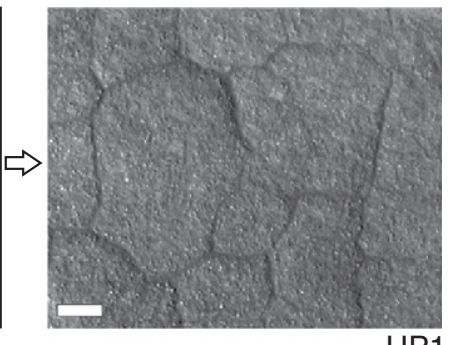

UP1
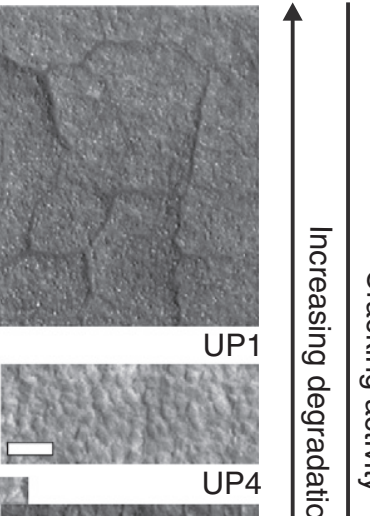

UP4

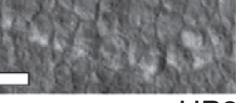

UP3

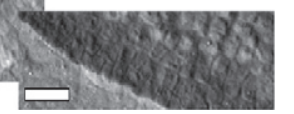

UP2

$\rightarrow$ Today

(lower obliquity)

Fig. 14. Schematic model of suggested polygon evolution in western Utopia Planitia, Mars, from a time of high obliquity conditions until today. Images on the right represent the current stages. The series of three images for UP2 and UP3 illustrate the development of small low- and high-centered polygonal networks, alternating arranged within a scalloped depression from north (left) to south (right) (for explanations see also Section 4.3). All scale bars are 20 m. North is up. (Details of PSP_001938_2265).

1966). It was shown by thermal modeling that summer temperatures in this region could reach $273 \mathrm{~K}$ even at obliquities of $35^{\circ}$, but such temperatures are more likely at higher obliquity (Ulrich et al., 2010). Very high temperatures in summer followed by an extreme temperature drop in winter could have led to deep crack penetration and the formation of larger polygons. Larger polygons, however, are also formed in material with lower ice content (Lachenbruch, 1966) as was discussed for the terrestrial polygons (Table 1). No clear relationship between polygon dimension and ground-ice content, which increases with latitude (e.g., Feldman et al., 2004), could be observed on Mars (Mangold et al., 2004; Mangold, 2005; Levy et al., 2009a). The size of the upland polygons (UP1) is consistent with the findings of the Gamma Ray Spectrometer (GRS) that only $\sim 4$ to $\sim 10$ wt.\% water-ice equivalent exists currently in the upper surface layer ( $<1 \mathrm{~m}$ depth) in the regions between $45^{\circ} \mathrm{S}$ and $45^{\circ} \mathrm{N}$ (Boynton et al., 2002; Mitrofanov et al., 2002; Feldman et al., 2004). If higher ground-ice contents than in the upper layer occur deeper than $1 \mathrm{~m}$, which was inferred from the dimension of the scalloped depressions (Morgenstern et al., 2007; Ulrich et al., 2010), seasonal thermal waves should not reach this depth at the present time (Mellon, 1997; Mangold et al., 2004). Thus, the process of thermal contraction cracking which formed the UP1 polygons is likely inactive today (Table 5 and Fig. 14). Only small shallow cracks observed within some polygon centers were likely to have been formed subsequently. It is not clear, however, how much ground ice existed during times of higher obliquity when these polygons were formed and ground ice was more stable in the upper surface layer than it is today (e.g., Hecht, 2002; Head et al., 2003). Currently, UP1 polygons are more influenced by degradation through sublimation. This process would be enhanced by the dark fine-grained material trapped within the polygon troughs. Furthermore, the enrichment of fine material within the large cracks could have led to the formation of sand-wedge-like structures (e.g., Sletten et al., 2003; Bockheim et al., 2009) (Table 5).

The small Martian polygons (UP2, UP3, and UP4) were formed after the depression formed and must therefore be relatively young (Fig. 14). If scallop formation is comparatively young, as stated e.g., by
Ulrich et al. (2010), these polygons are not older than 5 Myr and are most likely much younger (e.g., Levy et al., 2009a,b, 2010). Based on the geomorphometry of the low-centered polygons located on the north-facing slope of the depression (i.e., UP2), it was concluded that thermal contraction cracking is active there (Table 5) and that these polygons formed in fine-grained ice-rich material. This is in agreement with the suggestion of Lefort et al. (2009) that they formed in connection to an ice table, which is closer to the surface there than on the uplands and deepens towards the south-facing slope. The lower amount of insolation on the north-facing slope results in higher ground-ice stability. This would explain currently active thermal contraction cracking despite lower temperature gradients on this permanently-shaded part of the depression (Lefort et al., 2009). However, if ice-cemented material were to be exposed after scarp erosion (Ulrich et al., 2010), initial cracking could have occurred immediately afterwards (Fig. 14) and the small polygons could have been formed within a few tens of years (Mackay and Burn, 2002). The cracks would then fill with wind-blown material, forming sand-wedges. Furthermore, if thawing of ground-ice enhanced the scarp erosional process during higher obliquity conditions (Ulrich et al., 2010), a small occasional water supply likely led to the formation of composite wedges (e.g., Murton, 1996) and thus the development of upturning ridges beside the cracks. As the ice-table deepens towards the depression bottom (Lefort et al., 2009) and the ground-ice content is lowered accordingly, the activity of the UP2 polygons decreases or even ceases entirely at a greater distance from the scarp (e.g., Mellon, 1997) (Table 5 and Fig. 14). The high-centered polygons on the ridges inside the depression (UP3) are proposed to have originated by similar processes as the UP2 polygons, although they represent older evolutionary stages in context of the equatorward lateral depression formation and scarp erosion (Ulrich et al., 2010; Séjourné et al., 2011). After the ridges were formed, their exposed position led to an initial enhancement of sublimation within the previously-formed crack pattern, especially if composite wedges existed below the cracks. Accordingly, the age of the UP3 polygons increases towards the depression bottom (Fig. 14). They are further 
influenced by intensified erosion and degradation and thus changing geomorphology due to the aspect of the internal ridges as was identified by the statistics. The changing geomorphometry of the polygonal UP2 and UP3 networks within the depression (Table 5) is in agreement with the proposed lateral scarp formation in the equatorward direction (Ulrich et al., 2010; Séjourné et al., 2011). While the UP2 and UP3 polygons on the north-facing slope are slightly smaller, more regular, orthogonal, and more subdivided, those on the depression bottom towards the south-facing slope are bigger, much more degraded, more irregular, and rather hexagonal (Figs. 13 and 14). Moreover, the morphology of upturning ridges beside the outlining cracks of the low-centered UP2 polygons is consistent with the recent growth of sand wedges or even the hypothesis of composite-wedge formation during more benign conditions in the past. Levy et al. (2009b) suggested an alternative formation hypothesis to explain the elevation of mixed-center polygon shoulders. The location of sublimation would shift inside a polygon; sublimation would be enhanced within the polygon interior as the troughs become insulated from further deepening by the thickening of ice-depleted material therein, while the centers remain lessefficiently insulated. This could be an explanation for the UP4 polygonal network on the south-facing slope where no cracks and only single outlining ridges could be observed. The UP4 polygons show close similarities to the "brain terrain" discussed by Levy et al. (2009b). After a small initial crack network, superimpose upon the remnants of the upland polygonal cracks, was formed by permanent insolation and therefore relatively higher temperature gradients (Fig. 14), it is conceivable that the pattern was modified relatively quickly according to Levy et al. (2009b) by continuous ground-ice sublimation and subsidence of ice-depleted material. The UP4 polygonal field could be an expression of the flattening and recent surface stabilization by permanent insolation and continuous but slow ground-ice sublimation on the south-facing scalloped depression slope (Ulrich et al., 2010).

In summary, from the comparison of polygon geomorphometry alone it seems problematic to classify the Martian polygons as icewedge, sand-wedge, or sublimation polygons, not least because the Adventdalen polygons also show close similarities to sand-wedge or sublimation polygons in Antarctica (e.g., Péwé, 1959; Marchant et al., 2002; Sletten et al., 2003; Bockheim et al., 2009; Levy et al., 2010). If we consider the evolution of the UP polygons in the geomorphological context of the scalloped depression formation, it becomes obvious, however, that sand or even composite wedges are likely to be formed and that all the different polygonal fields represent different evolutionary stages within the landscape formation process (Fig. 14). Differing local and regional changes in climate and ground-ice conditions are reflected in their geomorphology and geomorphometric characteristics. Recent polygon development in western UP seems to be limited to the effects produced when smallscale local conditions allow active thermal contraction cracking (Table 5). Regionally, the UP polygons have been influenced by dry degradation processes such as ground-ice sublimation. As this is a very slow process, the polygon evolution in UP is currently almost stagnant compared to polygon evolution stimulated by the fastchanging environment in Adventdalen.

\section{Conclusion}

Thermal contraction polygons in different stages of evolution on Svalbard were used as terrestrial analogs to elucidate the processes of small-scale polygon formation in western Utopia Planitia, Mars. Quantitative terrain analyses on the basis of very-high-resolution remote-sensing data indicate a comparable thermal contraction cracking genesis of the small-scale polygons investigated on Mars, and allowed us to infer specific atmospheric and subsurface conditions which exist or existed in the past in relation to polygon formation on Mars. Both in Adventdalen and on Mars, polygon evolution is strongly related to regional and local landscape dynamics. On both Earth and Mars larger polygons were formed in the past during times when more favorable conditions allowed deep thermal contraction cracking. These polygons are currently degrading. The formation of composite wedges could have occurred in response to past orbital configurations of Mars, which led to the development of small low-centered polygons on north-facing scalloped depression slopes. These patterns show the closest analogy to ice-wedge polygons in Adventdalen. However, their location within the scalloped depressions probably allowed active thermal contraction cracking and possibly sand-wedge growth under current Martian climate conditions. On Earth ice-wedge polygons form due to the existence of liquid water, and are subsequently degraded by groundice thawing, while the present appearance of Martian polygons is primarily the result of dry degradation processes (i.e., sublimation).

The multivariate statistical approach was successfully applied to quantitatively validate the relationship between polygon geomorphometry and topographical parameters. Comparatively few environmental parameters could be extracted out of DEMs and used in the statistics as explanatory (i.e., environmental) variables, which results in the relatively high amount of unexplained variance in the polygon dataset. In future work, further parameters reflecting not only topography but also subsurface and climate conditions should be included in the statistics. Furthermore, in cooperation with other quantitative methods like spatial point pattern analysis (SPPA) (e.g., Dutilleul et al., 2009; Haltigin et al., 2010), a more detailed understanding of diverse polygonal geomorphometry can be achieved and linked to individual formation processes.

Our results demonstrate the difficulty of addressing the question of what factors govern the size and shape of polygons. These results emphasize the complex interaction of various factors such as air and ground temperature variations, subsurface conditions, and topography. More detailed analyses of physical properties influencing polygon evolution should be performed, and the individual subsurface and climatic conditions of genetically differing polygonal structures must be included in future quantitative terrain analyses. Field surveys of analog morphologies in terrestrial permafrost environments are the necessary complement and also provide the ground truth for remotesensing data analyses.

\section{Acknowledgment}

This research has been partly supported by the Helmholtz Association through the "Planetary Evolution and Life" research alliance. Field work on Svalbard would not have been possible without logistical support by the AWIPEV German-French research station. UNIS and the Norwegian Polar Institute generously provided transport and safety equipments for the field campaign in Adventdalen. Special thanks go to the other members of our field team, Harald Hiesinger, Dennis Reiss, Michael Zanetti (University of Münster), Lars Johansson, and Andreas Johnsson (University of Gothenburg). The analytical lab work was significantly supported by Ute Bastian (AWI Potsdam). We thank Matthias Grott (DLR Berlin) for assistance and fruitful discussions about the KD2 measurements. The efforts of all colleagues involved in HRSC-AX image acquisition and processing, in particular Frank Trauthahn and Frank Preusker (DLR Berlin), are highly appreciated. The continuing efforts and support of the HiRISE and CTX teams in making their data publicly available are gratefully acknowledged. We also thank Randy Kirk (USGS, Flagstaff, USA) and colleagues for kindly providing a HiRISE DEM of our Martian study site. The paper benefited by English proof-reading and valuable comments from Candace S. O'Connor (UAF, Fairbanks, Alaska). Finally, we would like to thank Goro Komatsu, Victor R. Baker, and the editor Takashi Oguchi for their reviews and helpful comments. 


\section{References}

Black, R.F., 1976. Periglacial features indicative of permafrost: ice and soil wedges. Quat. Res. 6, 3-26.

Bockheim, J.G., Kurz, M.D., Soule, A., Burke, A., 2009. Genesis of active sand-filled polygons in lower and central Beacon Valley, Antarctica. Permafrost Periglac. Process. 20, 295-308.

Borcard, D., Legendre, P., 2002. All-scale spatial analysis of ecological data by means of principal coordinates of neighbor matrices. Ecol. Model. 153, 51-68.

Borcard, D., Legendre, P., Drapeau, P., 1992. Partialling out the spatial component of ecological variation. Ecology 73, 1045-1055.

Borcard, D., Legendre, P., Avois-Jacquet, C., Tuomisto, H., 2004. Dissecting the spatial structure of ecological data at multiple scales. Ecology 87, 1826-1832.

Boynton, W.V., Feldman, W.C., Squyres, S.W., Prettyman, T.H., Brückner, J., Evans, L.G., Reedy, R.C., Starr, R., Arnold, J.R., Drake, D.M., Englert, P.A.J., Metzger, A.E., Mitrofanov, I., Trombka, J.I., d'Uston, C., Wänke, H., Gasnault, O., Hamara, D.K., Janes, D.M., Marcialis, R.L., Maurice, S., Mikheeva, I., Taylor, G.J., Tokar, R., Shinohara, C., 2002. Distribution of hydrogen in the near surface of Mars: evidence for subsurface ice deposits. Science 297, 81-85.

Brown, J., Ferrians Jr., O.J., Heginbottom, J.A., Melnikov, E.S., 1998. Circum-Arctic map of Permafrost and Ground-Ice Conditions. National Snow and Ice Data Center/World Data Center for Glaciology, Boulder, CO.

Bryant, I.D., 1982. Loess deposits in lower Adventdalen, Spitsbergen. Polar Res. 2, 93-103.

Burr, D.M., Tanaka, K.L., Yoshikawa, K., 2009. Pingos on Earth and Mars. Planet. Space Sci. $57,541-555$

Christiansen, H.H., 2005. Thermal regime of ice-wedge cracking in Adventdalen, Svalbard. Permafrost Periglac. Process. 16, 87-98

Christiansen, H.H., Etzelmüller, B., Isaksen, K., Juliussen, H., Farbrot, H., Humlum, O., Johansson, M., Ingeman-Nielsen, T., Kristensen, L., Hjort, J., Holmlund, P., Sannel, A.B.K., Sigsgaard, C., Åkerman, H.J., Foged, N., Blikra, L.H., Pernosky, M.A., Ødegård, R.S., 2010. The thermal state of permafrost in the Nordic Area during the International Polar Year 2007-2009. Permafrost Periglac. Process. 21, 156-181.

Dallmann, W.K., Kjærnet, T., Nøttvedt, A., 2001. Geomorphological and Quaternary Map of Svalbard. 1:100,000, Sheet C9G Adventdalen, Temakart No.31/32. Norwegian Polar Institute, Tromsø.

de Pablo, M.A., Komatsu, G., 2009. Possible pingo fields in the Utopia basin, Mars: geological and climatical implications. Icarus 199, 49-74.

Dutilleul, P., Haltigin, T.W., Pollard, W.H., 2009. Analysis of polygonal terrain landforms on Earth and Mars through spatial point patterns. Environmetrics 20, 206-220.

El Maarry, M.R., Markiewicz, W.J., Mellon, M.T., Goetz, W., Dohm, J.M., Pack, A., 2010. Crater floor polygons: desiccation patterns of ancient lakes on Mars? J. Geophys. Res. 115, E10006. doi:10.1029/2010JE003609.

Feldman, W.C. Prettyman, T.H. Maurice, S., Plaut, JJ. Bish, D.L, Vaniman, D.T. Mellon, M.T., Metzger, A.E., Squyres, S.W., Karunatillake, S., Boynton, W.V., Elphic, R.C., Funsten, H.O., Lawrence, D.J., Tokar, R.L., 2004. Global distribution of near-surface hydrogen on Mars. J. Geophys. Res. 109, E09006. doi:10.1029/2003JE002160.

Fortier, D., Allard, M., 2005. Frost-cracking conditions, Bylot Island, Eastern Canadian Artic archipelago. Permafrost Periglac. Process. 16, 145-161. doi:10.1002/ppp. 504.

Fortier, D., Allard, M., Shur, Y., 2007. Observation of rapid drainage system development by thermal erosion of ice wedges on Bylot Island, Canadian Arctic Archipelago. Permafrost Periglac. Process. 18, 229-243. doi:10.1002/ppp. 595.

French, H.M., 2007. The Periglacial Environment, 3rd ed. John Wiley, Chichester, U.K.

Gwinner, K., Scholten, F., Spiegel, M., Schmidt, R., Giese, B., Oberst, J., Heipke, C., Jaumann, R., Neukum, G., 2009. Derivation and validation of high-resolution digital elevation models from Mars Express HRSC data. Photogramm. Eng. Remote. Sens. $75,1127-1142$

Gwinner, K., Scholten, F, Preusker, F., Elgner, S., Roatsch, T, Spiegel, M., Schmidt, R, Oberst, J., Jaumann, R., Heipke, C., 2010. Topography of Mars from global mapping by HRSC high-resolution digital elevation models and orthoimages: characteristics and performance. Earth Planet. Sci. Lett. 294, 506-519.

Haltigin, T., Pollard, W., Dutilleul, P., 2010. Comparison of ground- and aerial-based approaches for quantifying polygonal terrain network geometry on Earth and Mars via spatial point pattern analysis. Planet. Space Sci. 58, 1636-1649.

Hanssen-Bauer, I., Førland, E.J., 1998. Long-term trends in precipitation and temperature in the Norwegian Arctic: can they be explained by changes in atmospheric circulation patterns? Clim. Res. 10,143-153.

Härtel, S., Christiansen, H.H., 2010. Formation and dynamics of Holocene syngenetic icewedge polygons in Adventdalen, Svalbard. Third European Conference on Permafrost. The University Center in Svalbard, Longyearbyen, Svalbard, Norway, p. 54

Hauber, E., Reiss, D., Ulrich, M., Preusker, F., Trauthan, F., Zanetti, M., Hiesinger, H., Jaumann, R., Johansson, L., Johnsson, A., Gasselt, S., Olvmo, M., 2011. Landscape evolution in Martian mid-latitude regions: insights from analogous periglacial landforms in Svalbard. In: Balme, M.R., Bargery, A.S., Gallagher, C.J., Gupta, S. (Eds.), Martian Geomorphology. Geol. Soc. Special Publications, London, pp. 111-131. doi:10.1144/SP356.7.

Hauber, E., Reiss, D., Ulrich, M., Preusker, F., Trauthan, F., Zanetti, M., Hiesinger, H., Jaumann, R., Johansson, L., Johnsson, A., Olvmo, M., Carlsson, E., Johansson, H.A.B., McDaniel, S., in press. Periglacial landscapes on Svalbard: Terrestrial analogues for cold-climate landforms on Mars. In: Garry, B., Bleacher, J. (Eds.), Analogs for planetary exploration. GSA Special Papers, Geol. Soc. Amer, USA.

Head, J.W., Mustard, J.F., Kreslavsky, M.A., Milliken, R.E., Marchant, D.R., 2003. Recent ice ages on Mars. Nature 426, 797-802.

Hecht, M., 2002. Metastability of liquid water on Mars. Icarus 156, 373-386.

Hiesinger, H., Head, J.W., 2000. Characteristics and origin of polygonal terrain in southern Utopia Planitia, Mars: results from Mars Orbiter Laser Altimeter and Mars Orbiter Camera data. J. Geophys. Res. 105, 11999-12022.
Humlum, O., Instanes, A., Sollid, J.L., 2003. Permafrost in Svalbard: a review of research history, climatic background and engineering challenges. Polar Res. 22, 191-215.

Isaksen, K., Holmlund, P., Sollid, J.L., Harris, C., 2001. Three deep alpine boreholes in Svalbard and Scandinavia. Permafrost Periglac. Process. 12, 13-25.

Jaumann, R., Neukum, G., Behnke, T., Jaumann, R., Neukum, G., Behnke, T., Duxbury, T.C. Eichentopf, K. Flohrer, J. Van Gasselt, S., Giese, B., Gwinner, K., Hauber, F, Hoffmann, H., Hoffmeister, A., Köhler, U., Matz, K.-D., McCord, T.B., Mertens, V., Oberst, J., Pischel, R., Reiss, D., Ress, E., Roatsch, T., Saiger, P., Scholten, F., Schwarz G., Stephan, K., Wählisch, M., the HRSC Co-Investigator Team, 2007. The highresolution stereo camera (HRSC) experiment on Mars Express: instrument aspects and experiment conduct from interplanetary cruise through the nominal mission. Planet. Space Sci., 55, pp. 928-952.

Jeppesen, J.W., 2001. Palæoklimatiske indikatorer for central Spitsbergen, Svalbard. Eksemplificeret ved studier af iskiler og deres værtssediment (Ice wedges and host sediments as palaeoclimatic indicators in central Spitsbergen, Svalbard) MSc thesis. University of Copenhagen, Denmark. (in Danish).

Kirk, R.L., Howington-Kraus, E., Rosiek, M.R., Anderson, J.A., Archinal, B.A., Becker, K.J., Cook, D.A., Galuszka, D.M., Geissler, P.E., Hare, T.M., Holmberg, I.M., Keszthelyi, L.P. Redding, B.L., Delamere, W.A., Gallagher, D., Chapel, J.D., Eliason, E.M., King, R. McEwen, A.S., 2008. Ultrahigh resolution topographic mapping of Mars with MRO HiRISE stereo images: meter-scale slopes of candidate Phoenix landing sites. J. Geophys. Res. 113, E00A24. doi:10.1029/2007JE003000.

Kreslavsky, M.A., Head, J.W., 2000. Kilometer-scale roughness of Mars: results from MOLA data analysis. J. Geophys. Res. 105 (E11), 26695-26711.

Kreslavsky, M.A., Head, J.W., 2002. Mars: nature and evolution of young latitude dependent water-ice-rich mantle. Geophys. Res. Lett. 29 (15). doi:10.1029/ 2002GL015392.

Lachenbruch, A.H., 1962. Mechanics of thermal contraction cracks and ice-wedge polygons in permafrost. Spec. Pap. Geol. Soc. Am. 70.

Lachenbruch, A.H., 1966. Contraction theory of ice-wedge polygons: a qualitative discussion. Proc. Permafrost Int. Conf., Lafayette, Indiana. Publ., 1287. U.S. Natl. Acad. Sci, Washington, D. C, pp. 63-71.

Lefort, A., Russell, P.S., Thomas, N., McEwen, A.S., Dundas, C.M., Kirk, R.L., 2009 Observations of periglacial landforms in Utopia Planitia with the High Resolution Imaging Science Experiment (HiRISE). J. Geophys. Res. 114, E04005. doi:10.1029/ 2008JE003264.

Levy, J., Head, J., Marchant, D., 2009a. Thermal contraction crack polygons on Mars: classification, distribution, and climate implications from HiRISE observations. J. Geophys. Res. 114, E01007. doi:10.1029/2008JE003273.

Levy, J., Head, J.W., Marchant, D.R., 2009b. Concentric crater fill in Utopia Planitia: history and interaction between glacial "brain terrain" and periglacial processes. Icarus 202, 462-476.

Levy, J., Marchant, D.R., Head, J.W., 2010. Thermal contraction crack polygons on Mars: a synthesis from HiRISE, Phoenix, and terrestrial analog studies. Icarus 206 229-252.

Liestøl, O., 1976. Pingos, springs and permafrost in Spitsbergen. Nor. Polarinst. Aarb. $1975,7-29$

Lønne, I., Nemec, W., 2004. High-arctic fan delta recording deglaciation and environment disequilibrium. Sedimentology 51, 553-589.

Lucchitta, B.K., 1981. Mars and Earth - comparison of cold-climate features. Icarus 45, 264-303.

Mackay, J.R., 1974. Ice-wedge cracks, Garry Island, Northwest Territories. Can. J. Earth Sci. $11,1366-1383$.

Mackay, J.R., 1980. Deformation of ice-wedge polygons, Garry Island, Northwest Territories. Geol. Surv. Can. 80 (1A), 287-291.

Mackay, J.R., 1992. The frequency of ice-wedge cracking (1967-1987) at Garry Island, western Arctic Coast, Canada. Can. J. Earth Sci. 29, 236-248.

Mackay, J.R., 2000. Thermally induced movements in ice-wedge polygons, Western Arctic Coast: a long-term study. Géogr. Phys. Quatern. 54, 41-68.

Mackay, J.R., Burn, C.R., 2002. The first 20 years (1978-1979 to 1998-1999) of icewedge growth at the Illisarvik experimental drained lake site, western Arctic coast, Canada. Can. J. Earth Sci. 39, 95-111.

Malmström, B., Nordström, S., Palmér, O., 1973. Iskilpolygoner i Adventdalen, Spetsbergen (Ice-wedge polygons in Adventdalen, Spitsbergen). In: Svensson, H., Hellden, U., Malmström, B., Nordström, S., Palmér, O., Åhman, R., Åkerman, J. (Eds.), Studier i periglacial geomorfologi på Spetsbergen. Rapporter och notiser 15. Lunds Univerisitets, Naturgeografiska Institution, pp. 4-26 (in Swedish)

Mangerud, J., Bolstad, M., Elgersma, A., Helliksen, D., Landvik, J.Y., Lønne, I., Lycke, A.K., Salvigsen, O., Sandahl, T., Svendsen, J.I., 1992. The last glacial maximum on Spitsbergen, Svalbard. Quat. Res. 38, 1-39.

Mangold, N., 2005. High latitude patterned grounds on Mars: classification, distribution and climatic control. Icarus 174, 336-359.

Mangold, N., Maurice, S., Feldman, W.C., Costard, F., Forget, F., 2004. Spatial relationships between patterned ground and ground ice detected by the neutron spectrometer on Mars. J. Geophys. Res. 109, E8. doi:10.1029/2004JE002235.

Marchant, D.R., Head, J.W., 2007. Antarctic Dry Valleys: microclimate zonation, variable geomorphic processes, and implications for assessing climate change on Mars. Icarus 192, 187-222.

Marchant, D.R., Lewis, A., Phillips, W.C., Moore, E.J., Souchez, R., Landis, G.P., 2002. Formation of patterned-ground and sublimation till over Miocene glacier ice in Beacon Valley, Antarctica. Geol. Soc. Am. Bull. 114, 718-730.

Matsuoka, N., 1999. Monitoring of thermal contraction cracking at an ice-wedge site, central Spitsbergen. Polar Geosci. 12, 258-271.

Matsuoka, N., Hirakawa, K., 1993. Critical polygon size for ice-wedge formation in Svalbard and Antarctica. Beijing Proceedings of the Sixth International Conference on Permafrost, 1, pp. 449-454. 
McEwen, A.S., Eliason, E.M., Bergstrom, J.W., Bridges, N.T., Hansen, C.J., Delamere, W.A. Grant, J.A., Gulick, V.C., Herkenhoff, K.E., Keszthelyi, L., Kirk, R.L., Mellon, M.T. Squyres, S.W., Thomas, N., Weitz, C.M., 2007. Mars Reconnaissance Orbiter's HighResolution Imaging Science Experiment (HiRISE). J. Geophys. Res. 112, E05S02. doi:10.1029/2005JE002605.

McEwen, A.S., et al., 2010. The High Resolution Imaging Science Experiment (HiRISE) during MRO's Primary Science Phase (PSP). Icarus 205, 2-37.

Meier, K.D., Thannheiser, D., 2009. Gletscher und Permafrost in Nordenskiøldland, Spitzbergen, als potentielle Klimaindikatoren. Hamburger Beiträge zur Physischen Geographie und Landschaftsökologie 20

Mellon, M.T., 1997. Small-scale polygonal features on Mars: seasonal therma contraction cracks in permafrost. J. Geophys. Res. 102 (E11), 25617-25628.

Mellon, M.T., Arvidson, R.E., Marlow, J.J., Phillips, R.J., Asphaug, E., 2008. Periglacial landforms at the Phoenix landing site and the northern plains of Mars. J. Geophys. Res. 113. doi:10.1029/2007JE003039.

Mitrofanov, I., Anfimov, D., Kozyrev, A., Litvak, M., Sanin, A., Tret'yakov, V., Krylov, A Shvetsov, V., Boynton, W., Shinohara, C., Hamara, D., Saunders, R.S., 2002. Maps of subsurface hydrogen from the High Energy Neutron Detector, Mars Odyssey Science 297, 78-81.

Morgenstern, A., Hauber, E. Reiss, D. van Gasselt, S., Grosse, G., Schirrmeister, L., 2007. Deposition and degradation of a volatile-rich layer in Utopia Planitia and implications for climate history on Mars. J. Geophys. Res. 112, E06010. doi:10.1029/2006JE002869.

Murton, J.B. 1996. Morphology and paleoenvironmental significance of Quarternary sand veins, sand wedges, and composite wedges, Tutktoyaktuk coastland, western Arctic Canada. J. Sediment. Res. 66, 17-25.

Mustard, J.F., Cooper, C.D., Rifkin, M.K., 2001. Evidence for recent climate change on Mars from the identification of youthful near-surface ground ice. Nature 412, 411-414.

Péwé, T.L., 1959. Sand wedge polygons (Tesselations) in the McMurdo Sound Region, Antarctica. Am. J. Sci. 257, 545-552.

Pina, P., Saraiva, J., Bandeira, L., Antunes, J., 2008. Polygonal terrains on Mars: contribution to their geometric and topological characterization. Planet. Space Sci. $56,1919-1924$.

Plug, L.J., Werner, B.T., 2001. Fracture networks in frozen ground. J. Geophys. Res. 106 (B5), 8599-8613.

Roberts, D.W., 1986. Ordination on the basis of fuzzy set theory. Vegetatio 66, 123-131. Romanovskii, N.N., 1977. Formirovanie poligonal'no-zhil'nykh struktur (Formation of polygonal wedge-structures). Novosibirsk, Nauka. (in Russian).

Romanovskii, N.N., 1985. Distribution of recently active ice and soil wedges in the USSR In: Church, M., Slaymaker, O. (Eds.), Field and Theory; Lectures in Geocryology. University of British Columbia Press, Vancouver, pp. 154-165.

Ross, N., Brabham, P.J., Harris, C., Christiansen, H.H., 2007. Internal structure of open system pingos, Adventdalen, Svalbard: the use of resistivity tomography to assess ground-ice conditions. J. Environ. Eng. Geophys. 12, 113-126.

Rossbacher, L.A., 1986. Nearest-neighbour analysis: a technique for quantitative evaluation of polygonal ground patterns. Geogr. Ann. A 68, 101-105.

Scholten, F., Gwinner, K., Roatsch, T., Matz, K.-D., Wählisch, M., Giese, B., Oberst, J. Jaumann, R., Neukum, G., the HRSC Co-Investigator Team, 2005. Mars Express HRSC data processing - methods and operational aspects. Photogramm. Eng. Remote. Sens. 71, 1143-1152.
Seibert, N.M. Kargel, J.S., 2001. Small-scale Martian polygonal terrain: implications for liquid surface water. Geophys. Res. Lett. 28, 899-902.

Séjourné, A., Costard, F., Gargani, J., Soare, R.J., Fedorov, A., Marmo, C., 2011. Scalloped depressions and small-sized polygons in western Utopia Planitia, Mars: a new formation hypothesis. Planet. Space Sci. 59, 412-422.

Sletten, R.S., Hallet, B., Fletcher, R.C., 2003. Resurfacing time of terrestrial surfaces by the formation and maturation of polygonal patterned ground. J. Geophys. Res. 108 (E4), 8044. doi:10.1029/2002JE001914.

Soare, R.J., Burr, D.M., Wan Bun Tseung, J.M., 2005. Possible pingos and a periglacia landscape in northwest Utopia Planitia. Icarus 174, 373-382.

Sørbel, L., Tolgensbakk, J., 2002. Ice-wedge polygons and solifluction in the Adventdalen area, Spitsbergen, Svalbard. Nor. Geogr. Tidsskr. 56, 62-66.

Sørbel, L., Tolgensbakk, J., Hagen, J.O., Høgvard, K., 2001. Geomorphological and Quaternary Map of Svalbard. 1:100,000, Sheet C9Q Adventdalen, Temakart No.31/ 32. Norwegian Polar Institute, Tromsø.

Svensson, H., 1971. Pingos i yttre delen av Adventdalen (Pingos in outermost Adventdalen valley). Norsk Polarinstitutt rbok 1969. Oslo 168-174 (in Norwegian).

Sweetman, J.N., Rühland, K.M., Smol, J.P., 2010. Environmental and spatial factors influencing the distribution of cladocerans in lakes across the central Canadian Acrtic treeline region. J. Limnol. 69, 76-87.

Tanaka, K.L., Skinner, J.A., Hare, T.M., 2005. Geologic map of the northern plains of Mars. 1:15,000,000, U. S. Geol. Surv. Sci. Invest. Map 2888.

Tolgensbakk, J., Sørbel, L., Høgvard, K., 2001. Adventdalen, Geomorphological and Quaternary Geological Map of Svalbard. 1:100,000, Spitsbergen sheet C9Q Temakart No. 32. Norwegian Polar Institute, Tromsø.

Ulrich, M., Morgenstern, A., Günther, F., Reiss, D., Bauch, K.E., Hauber, E., Rössler, S. Schirrmeister, L., 2010. Thermokarst in Siberian ice-rich permafrost: comparison to asymmetric scalloped depressions on Mars. J. Geophys. Res. 115, E10009. doi:10.1029/2010JE003640.

van Gasselt, S., Reiss, D., Thorpe, A.K., Neukum, G., 2005. Seasonal variations of polygonal thermal contraction crack patterns in a south polar trough, Mars. J. Geophys. Res. 110 (E8), E08002. doi:10.1029/2004JE002385.

Washburn, A.L., 1979. Geocryology - A Survey of Periglacial Processes and Environments. E. Arnold Ltd., London.

Wewel, F., Scholten, F., Gwinner, K., 2000. High Resolution Stereo Camera (HRSC) Multispectral 3D-data acquisition and photogrammetric data processing. Can. J Remote. Sens. 26, 466-474.

Williams, P.J., Smith, M.W., 1989. The Frozen Earth: Fundamentals of Geocryology. Cambridge Univ. Press, Cambridge.

Yershov, E.D., 2004. General Geocryology; Studies in Polar Research. Cambridge Univ, Press, New York.

Yoshikawa, K., 2003. Origin of the polygons and thickness of Vastitas Borealis Formation in Western Utopia Planitia on Mars. Geophys. Res. Lett. 30, 1603. doi:10.1029/ 2003 GL017165.

Yoshikawa, K., Nakamura, T., 1996. Pingo growth ages in the delta area, Adventdalen, Spitsbergen. Polar Record 32, 347-352.

Zuur, A.F., Ieno, E.N., Smith, G.M., 2007. Statistics for Biology and Health; Analyzing Ecological Data. Springer, New York. 